\title{
Limnoterrestrial 'Typhloplanidae' (Rhabdocoela, Platyhelminthes), with the description of four new species and a new genus
}

\author{
Albrecht M. HOUBEN ${ }^{\circledR}{ }^{1}$, Marlies MONNENS ${ }^{{ }^{2} \text {,* }}$, Willem PROESMANS ${ }^{{ }^{\circledR}}$ \\ \& Tom J. ARTOIS ${ }^{\oplus 4}$ \\ ${ }^{1,2,4}$ Hasselt University, Centre for Environmental Sciences, Research Group Zoology: Biodiversity \& \\ Toxicology, Agoralaan Gebouw D, B-3590 Diepenbeek, Belgium. \\ ${ }^{3}$ UMR Agroécologie, INRAE, 17 Rue Sully, F-21065 Dijon, France. \\ *Corresponding author: marlies.monnens@uhasselt.be \\ ${ }^{1}$ Email: albrecht.houben@gmail.com \\ ${ }^{3}$ Email: willem.proesmans@gmail.com \\ ㄹEmail: tom.artois@uhasselt.be \\ ${ }^{1}$ urn:1sid:zoobank.org:author:47A2BBE9-0820-4E83-B8BD-B41 A66C214ED
${ }^{2}$ urn:1sid:zoobank.org:author:782F71E0-EF84-48DA-BE72-8E205CB78EAC
${ }^{3}$ urn:1sid:zoobank.org:author:41B81434-06EE-4BD0-8DCE-4DE73F2A6B30
${ }^{4}$ urn:Isid:zoobank.org:author:2EDDE35C-A2F0-4CA2-84AA-2A7893C40AC4
}

\begin{abstract}
Four new species of limnoterrestrial rhabdocoels ('Typhloplanidae' Graff, 1905) are described. One of these - Faunulus nielsi Houben, Proesmans \& Artois gen. et sp. nov. - could not be unambiguously placed within an existing genus. Faunulus nielsi most closely resembles species of the genus Adenocerca Reisinger, 1924 but can be clearly distinguished by the position of the testes. The three other new species described are Bryoplana belgica Houben, Proesmans \& Artois sp. nov., Hoplopera isis Houben, Proesmans \& Artois sp. nov., and Protoplanella leiae Houben, Proesmans \& Artois sp. nov. All three belong to the subfamily 'Protoplanellinae' Reisinger, 1924 and are distinguished based on a detailed description of the reproductive system. Finally, new data are provided for nine other, known typhloplanids: Adenocerca minima Kolasa, 1981; Chorizogynopora italica Kolasa, 1981; Hoplopera opaca Reisinger, 1924; K. subterranea Reisinger, 1933; Krumbachia virginiana (Kepner \& Carter, 1931) Ruebush, 1938; Olisthanellinella rotundula Reisinger, 1924; Prorhynchella minuta Ruebush, 1939; Protoplanella simplex Reisinger, 1924; and Ventrociliella romanae Kolasa, 1977. A detailed comparison of our material of $V$. romanae to what is described for Bockia deses Reisinger, 1924, leads us to consider the latter a nomen dubium.
\end{abstract}

Keywords. Plathelminthes, flatworms, systematics, taxonomy, biodiversity.

Houben A.M., Monnens M., Proesmans W. \& Artois T.J. 2022. Limnoterrestrial 'Typhloplanidae' (Rhabdocoela, Platyhelminthes), with the description of four new species and a new genus. European Journal of Taxonomy 798: 70-102. https://doi.org/10.5852/ejt.2022.798.1671 


\section{Introduction}

Apart from the rather well-known land planarians (Geoplanidae Stimpson, 1857), free-living flatworms are often conceived of as aquatic animals, living in all types of (submersed) marine, freshwater, and brackish water habitats. As a result, taxonomic and faunistic studies on flatworms almost exclusively focus on these types of environments. Few studies have addressed the microturbellarian diversity in limnoterrestrial habitats. Sometimes called 'terrestrial' or 'semi-terrestrial' habitats in literature, we here refer to moist, terrestrial environments subject to unpredictable periods of desiccation, e.g., mosses or leaf litter. The rare studies focussing on these habitats revealed a fascinating diversity of animals. An overview is presented by Houben et al. 2015.

Most described limnoterrestrial microturbellarians belong to Rhabdocoela Ehrenberg, 1831, one of the most species-rich and ecologically diverse groups of free-living flatworms (Tyler et al. 2006-2021; WoRMS 2021). Unlike most rhabdocoels, these animals rarely possess sclerotised structures that may aid in species identification. As such, taxonomic studies by necessity rely on manual reconstructions of the (soft) internal organs based on histologically stained sections. This time-consuming task explains the scarcity of taxonomic publications concerning limnoterrestrial rhabdocoels, despite their common occurrence (Van Steenkiste et al. 2010). Indeed, most species were described by only two authors, and then even in very few studies dating back several decades (Reisinger 1924; Kolasa 1977; 1981a, 1981b). As a result, only about 50 species out of an odd 1700 described rhabdocoels are limnoterrestrial (Tyler et al. 2006-2021; WoRMS 2021), likely representing a minimal fraction of the biodiversity encompassed by these animals.

Unsurprisingly in view of the above, most limnoterrestrial rhabdocoels are only known from their original description (for an overview, see Van Steenkiste et al. 2010). Traditionally, most of these species were assigned to 'Protoplanellinae' Reisinger, 1924, a heterogeneous subfamily of 'Typhloplanidae' Graff, 1905 (Dalytyphloplanida, Willems, Wallberg, Jondelius, Littlewood, Backeljau, Schockaert \& Artois, 2006). Van Steenkiste et al. 2013 included four representatives of 'Protoplanellinae' in the first-ever molecular phylogenetic analysis covering this taxon. Even from this small dataset, it already appears that neither 'Protoplanellinae' nor 'Typhloplanidae' constitute monophyletic groupings (Fig. 1). This finding was confirmed from a more extensive dataset in the $\mathrm{PhD}$ thesis of the first author (Houben, 2013, unpublished), and these taxa still await revision.

In the last fifteen years, members of our research group have collected microturbellarians from their limnic and limnoterrestrial habitats in Europe and North America. During these sampling campaigns, we have uncovered a large diversity of rhabdocoel species belonging to different dalytyphloplanid subtaxa. In this contribution, we treat those species traditionally classified within 'Typhloplanidae', including one new species that could not be placed in any existing genus. For the latter, we hence propose a new genus. As most typhloplanids are only known from their original description, which in several cases lacks detail, we provide as much new data on morphology as could be retrieved from the newly collected material.

\section{Material and methods}

The material was collected by A.M. Houben and W. Proesmans during a sampling campaign in Austria from 21 to 30 August 2011 and during several small sampling trips in and around Belgium. Additional material was collected by Dr N. Van Steenkiste during a sampling trip in southern Ontario (Canada) and Alabama (USA) from May to June 2009. In all cases, vegetation was collected by hand and transported to the lab in a closed plastic bag to retain moisture. Samples were processed as soon as possible using the Bearmann pan (Townshend 1963) or oxygen depletion method (Schockaert 1996). Specimens were retrieved under a stereo microscope and then photographed and studied alive under a 
compound microscope. Afterwards, specimens were fixed in hot $\left(50^{\circ} \mathrm{C}\right)$ Bouin's fixative, embedded in paraffin, serially sectioned ( 3 or $4 \mu \mathrm{m}$ ), and stained with Heidenhain's haematoxylin, using erythrosin as counterstain. For species with sclerotised parts, any available additional specimens were whole mounted in lactophenol. Drawings were made with the aid of a camera lucida, using Nomarski inference contrast for the study of sclerotised structures.

Unfortunately, no type or reference material was deposited for most of the described species we collected. Only for Adenocerca minima Kolasa, 1981; Chorizogynopora italica Kolasa, 1981; and Ventrociliella romanae Kolasa, 1977, the original descriptions specifically mention if and where reference material was deposited. For A. minima, Kolasa (1981b) clearly states that the holotype is not preserved and for C. italica, a deposition in the collection of the Department of Animal Morphology, Poznan is mentioned (slide no. 222-1102, see Kolasa 1981b). The material for V. romanae consists of two sectioned specimens,

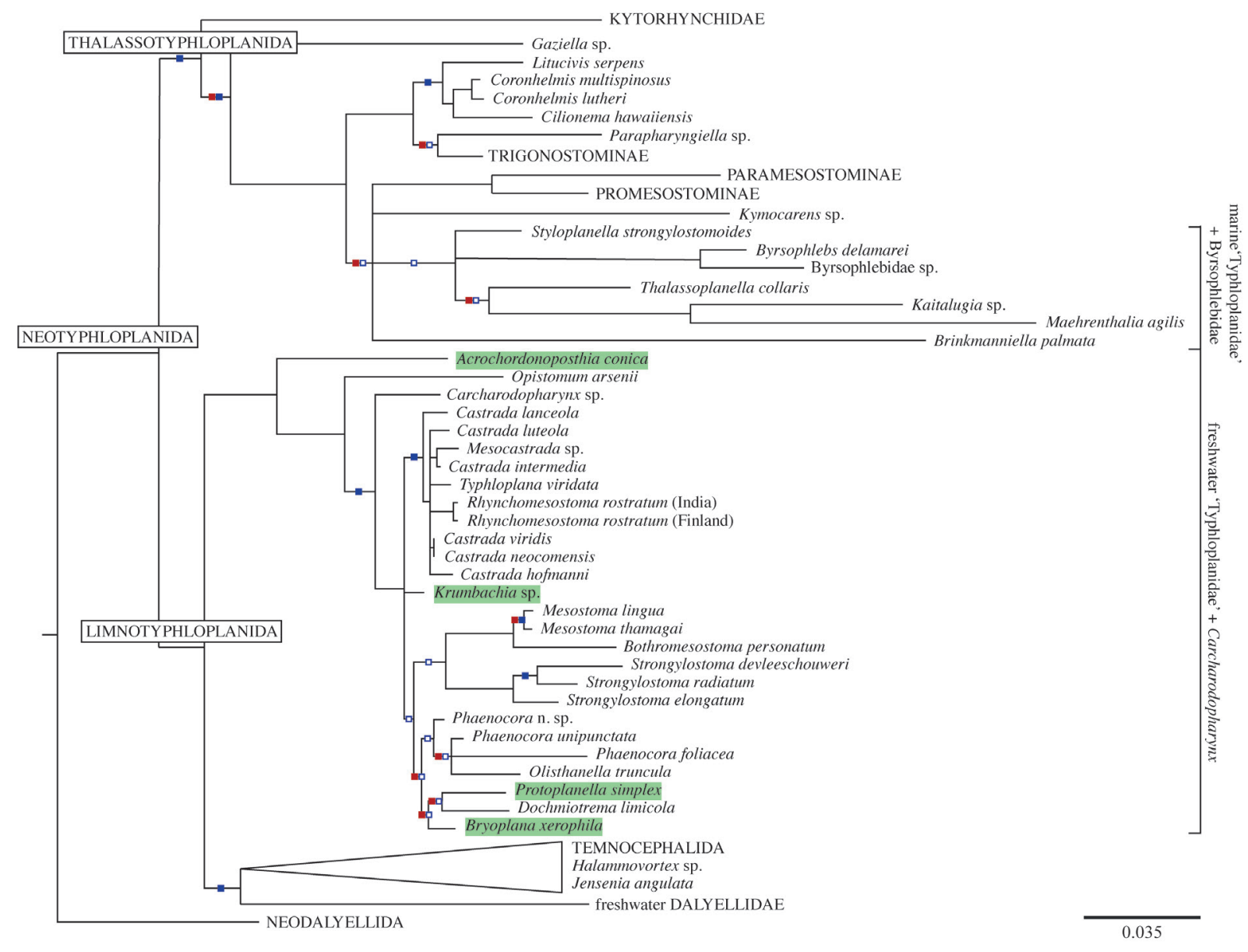

Fig. 1. Interrelationships of Dalytyphloplanida Willems, Wallberg, Jondelius, Littlewood, Backeljau, Schockaert \& Artois, 2006 summarised after the maximum likelihood/Bayesian analyses of Van Steenkiste et al. (2013), demonstrating the non-monophyly of 'Protoplanellinae' Reisinger, 1924 and 'Typhloplanidae' Graff, 1905. Species traditionally ascribed to 'Protoplanellinae' are marked in green. Clades with bootstrap values (bp) and posterior probabilities (pp) below threshold have been collapsed (bp $<70, \mathrm{pp}<0.90$ ). Symbols on branches denote support values: $\mathbf{a}=0.90<\mathrm{pp}<1 ; \square=\mathrm{pp}<0.90$; - $=100<\mathrm{bp}<70 ; \square=\mathrm{bp}<70$. Unmarked branches indicate a maximally supported clade. Branch lengths denote the number of nucleotide substitutions per site. 
which were deposited as type (and therefore syntypes) in the collection of the Agrobiology Department, Poznan (Kolasa 1977). We repeatedly contacted the zoological museum and the two above-mentioned departments in Poznań, however, without receiving any response.

Reisinger (1924, 1933) described all other known species treated in this contribution, except for Prorhynchella minuta Ruebush, 1939. The deposition or preservation of material from Reisinger was never mentioned; however, strong indications suggest that any existing material from Graz was destroyed during the Second World War (Rieger 1974). Additionally, contacting the Institute of Zoology at the Karl-Franzens-Universität in Graz yielded no response. Therefore, to our knowledge, type material of all these species was not deposited, or otherwise is lost (also see Houben et al. 2015).

As species identification is based on subtle details in the construction of the genital system, a thorough comparison of sectioned specimens is necessary. Therefore, when all requirements for neotype designation are met (ICZN 1999: Art. 75), type material is imperative, and we deemed it appropriate to designate neotypes. As such, we have designated neotypes for Krumbachia subterranea Reisinger, 1933, and Protoplanella simplex Reisinger, 1924. We refrain from designating a neotype for Adenocerca minima, Hoplopera opaca Reisinger, 1924; Olisthanellinella rotundula Reisinger, 1924; and Prorhynchella minuta. For the latter, we have found our material about $1600 \mathrm{~km}$ from the original locality mentioned by Ruebush (1939). Since the type locality and our locations are so far apart, the qualifying conditions for designating a neotype were not met (ICZN 1999: Art. 75.3.6). For A. minima, no neotype is designated for the time being due to very subtle differences between our material and the original description that require further investigation. In the genus Hoplopera Reisinger, 1924, the sclerotised structure of the bursa is the most important feature distinguishing all known species from each other; however, this structure cannot be observed in detail in the specimen of $H$. opaca we collected. Also for $O$. rotundula, we have no material showing all diagnostic features (for detailed information, see taxonomical account).

Holotypes of the new species and neotypes will be deposited in the Finnish Museum of Natural History (FMNH). All other material, including paratypes, is stored in the collections of the research group 'Zoology: Biodiversity and Toxicology' of Hasselt University (HU).

\section{Abbreviations for morphological terms}

$$
\begin{aligned}
\text { ag } & =\text { atrial glands } \\
\mathrm{ar} & =\text { adenal rhabdites } \\
\mathrm{br} & =\text { brain } \\
\mathrm{bs} & =\text { bursal stalk } \\
\mathrm{bu} & =\text { bursa } \\
\mathrm{cb} & =\text { ciliary band } \\
\mathrm{cir} & =\text { cirrus } \\
\mathrm{co} & =\text { copulatory organ } \\
\mathrm{cp} & =\text { ciliated pit } \\
\mathrm{cs} & =\text { crown spines } \\
\mathrm{de} & =\text { ejaculatory duct } \\
\mathrm{dr} & =\text { dermal rhabdites } \\
\mathrm{fd} & =\text { female duct } \\
\mathrm{fg} & =\text { female glands } \\
\mathrm{ga} & =\text { genital atrium } \\
\mathrm{gd} & =\text { gonoduct } \\
\mathrm{gg} & =\text { prostate glands } \\
\mathrm{gl} & =\text { glands } \\
\mathrm{gp} & =\text { gonopore }
\end{aligned}
$$




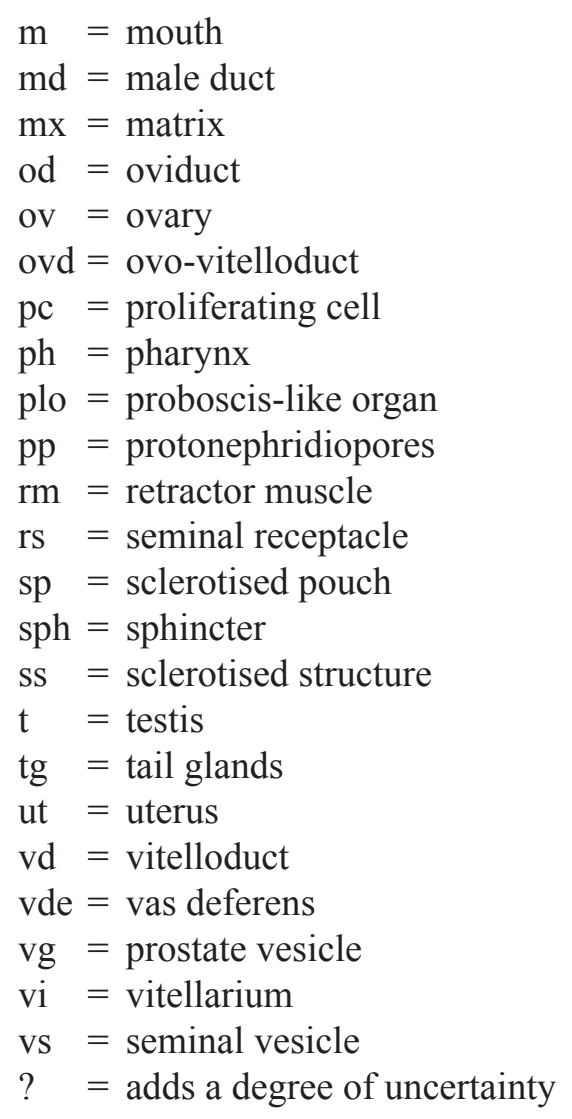

\section{Results and discussion}

An extensive molecular phylogenetic analysis of limnoterrestrial rhabdocoels is lacking to date. Few species were included in the analyses of Van Steenkiste et al. 2013, already showing that the current classification does not reflect the evolutionary history of these animals (Fig. 1). No specimens were available to conduct a new DNA-based analysis in the present study. Hence, the following taxonomical discussion is exclusively based on morphology. In the absence of a comprehensive molecular dataset, we refrain from postulating a new classification for these species and for the time being assign our species to the traditional subtaxa.

In 'Typhloplanidae' and 'Protoplanellinae', classification proved extremely complex in the past, which is reflected in the fact that there are several monotypic genera, mostly diagnosed by a unique combination of characters. In the following section, we strictly follow the morphological discussion by Van Steenkiste et al. (2010), which is employed in the identification key provided by these authors (Van Steenkiste et al. 2010: 11). In the taxonomic account, we apply the phylogenetic species concept as defined by Nixon \& Wheeler, 1990, i.e., "[a species is] the smallest aggregation of populations or lineages diagnosable by a unique combination of character states in comparable individuals." 
HOUBEN A.M. et al., Systematics of limnoterrestrial 'Typhloplanidae'

Dalytyphloplanida Willems, Wallberg, Jondelius, Littlewood, Backeljau, Schockaert \& Artois, 2006

Family ‘Typhloplanidae’ Graff, 1905

Genus Faunulus Houben, Proesmans \& Artois gen. nov.

urn:1sid:zoobank.org:act:18E72BA0-D92B-4504-8E17-BD6497247BCA

\section{Type species}

Faunulus nielsi Houben, Proesmans \& Artois gen. et sp. nov.

\section{Diagnosis}

'Typhloplanidae' with adenal rhabdites in two anterior tracts, dermal rhabdites could be present distally. Eyes absent. Pharynx slanted obliquely forward and in the central body part. With rod-shaped glands at rostral and caudal body end. Testes differ in size and lie anterior to the pharynx. Copulatory organ with straight, armed cirrus. Seminal receptacle inside of the oviduct. Bursa copulatrix absent.

\section{Etymology}

The genus name refers to the habitat where this taxon was found and is derived from the Latin 'Faunulus' (m.), meaning 'forest dweller'.

Faunulus nielsi Houben, Proesmans \& Artois gen. et sp. nov. urn:1sid:zoobank.org:act:E8B0D042-259A-427D-8F29-5DB6ED8C8411

Fig. 2

\section{Diagnosis}

Provisionally the same diagnosis as the genus.

\section{Etymology}

The species epithet is dedicated to Niels Houben, son of the first author (A.M. Houben).

\section{Material examined}

\section{Holotype}

AUSTRIA - 1 spec., live observations and sagittal sections; Kreuzberg near Weyer; 47 $51^{\prime} 36^{\prime \prime} \mathrm{N}$, 14³9'09" E; 29 Aug. 2011; A.M. Houben and W. Proesmans leg.; forest soil of Pinus, Sambucus, Corylus, and Cornus; KV.686; FMNH.

\section{Paratypes}

AUSTRIA - 2 specs, live observations, one of which whole mounted; same collection data as for holotype; paratype no. 821; HU.

\section{Description}

Specimens about $1 \mathrm{~mm}$ long. The body shape is pointed anteriorly and blunt to rounded posteriorly (see Fig. 2A). On free-swimming specimens, a small tail can be observed. Both anterior and posterior ends possess very typical, strongly eosinophilic glands that appear rod-shaped, like big rhabdites, and are situated more or less parallel to each other. Rostrally, rhabdite glands (Fig. 2A: ar) are present and arranged in two groups. The distal part of the epidermis is completely filled with coarse, strongly eosinophilic secretions, which probably are dermal rhabdites (Fig. 2B: dr?). The protonephridiopores were not observed with certainty. The slightly forward slanted rosulate pharynx (Fig. 2A: ph) is located centrally. 
The gonopore (Fig. 2A-B: gp) is situated at $\pm 65 \%$ of the body and connected to a genital atrium (Fig. $2 \mathrm{~A}-$ $\mathrm{B}$ : ga) that is surrounded by muscles, although their orientation could not be observed with certainty.

The paired, differently sized testes (Fig. 2A: t) lie in front of the pharynx and ventral to the paired vitellaria (Fig. 2A-B: vi). One testis is relatively large, while the other is barely visible. The paired vasa
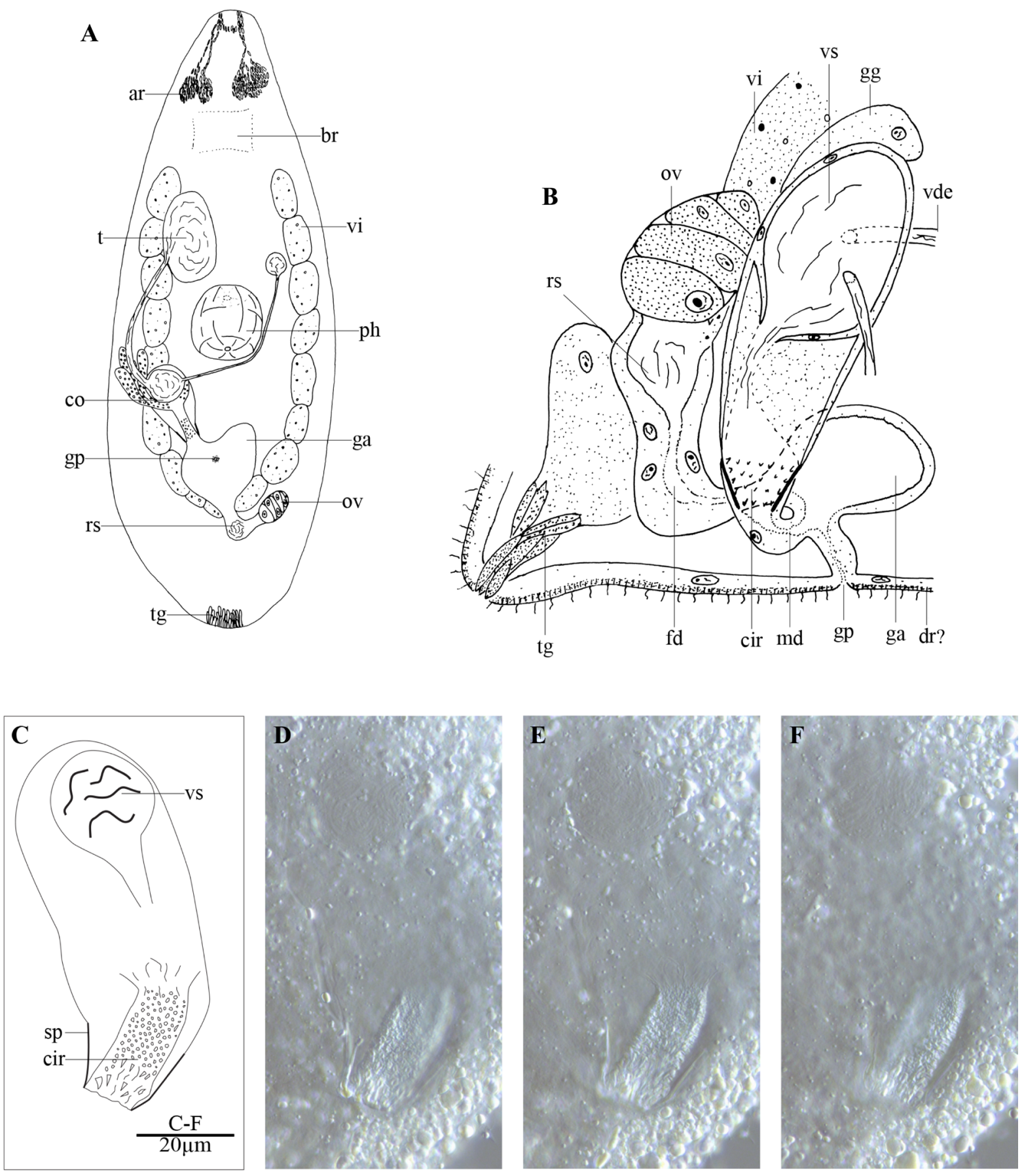

Fig. 2. Faunulus nielsi Houben, Proesmans \& Artois gen. et sp. nov. A. Internal organisation of a live specimen, B. Reconstruction of reproductive organs based on sagittal sections of the holotype (KV.686). C-F. Male copulatory organ of the paratype (paratype no. 821). 
deferentia (Fig. 2B: vde) enter the copulatory organ laterally (Fig. 2A: co). Two layers of spiral muscles surround the $50 \mu \mathrm{m}$ long copulatory organ, which bears an intracapsular seminal vesicle (Fig. $2 \mathrm{~B}-\mathrm{C}$ : vs) and a cirrus (Fig. 2B-C: cir). Large, coarse-grained, extracapsular eosinophilic glands (Fig. 2B: gg) are associated with the copulatory organ, although the point of entry remains uncertain. The $30 \mu \mathrm{m}$ long cirrus is more or less straight and covered with spines in its distal part (see Fig. 2B-F: cir). The most distal part of the cirrus bears the larger spines and is enveloped in a conical, sclerotised pouch (Fig. $2 \mathrm{C}$ : $\mathrm{sp})$.

The female duct (Fig. 2B: fd) is relatively long and lined with a high, nuclear epithelium. Proximally it widens into a seminal receptacle (Fig. 2B: rs) that receives the oviduct and the vitelloduct.

\section{Discussion}

Faunulus nielsi Houben, Proesmans \& Artois gen. et sp. nov. strongly resembles species of Adenocerca Reisinger, 1924 because of the combination of following features: centrally positioned pharynx, presence of tail glands and a spiny cirrus, and absence of a bursa (Van Steenkiste et al. 2010). However, F. nielsi Houben, Proesmans \& Artois gen. et sp. nov. differs from all species of Adenocerca in having testes that lie rostral to the pharynx. In all species of Adenocerca, they are situated posterior to the pharynx and lie next to the copulatory organ. Moreover, there is a difference in size between the two testes of F. nielsi Houben, Proesmans \& Artois gen. et sp. nov., which was never reported for Adenocerca. This size difference is consistent for all observed specimens. All species of Adenocerca either have no dermal rhabdites (Adenocerca teshirogii Kolasa, 1981) or dermal rhabdites occurring throughout the whole epidermis. Conversely, what we assume are dermal rhabdites occur solely in the caudal body part of F. nielsi Houben, Proesmans \& Artois gen. et sp. nov. Because of the unique combination of features present in the new species described, we find it justified to erect a new genus within 'Typhloplanidae'.

\section{Remarks}

Animals seem to feed on rotifers since trophi were found in the gut.

$$
\text { Genus Ventrociliella Kolasa, } 1977
$$

\section{Ventrociliella romanae Kolasa, 1977}

Fig. 3

\section{Material examined}

AUSTRIA • 1 spec., serially sectioned; near Graz, Hohe Rannach; 4709'53" N, 1524'50" E; 26 Aug. 2011; A.M. Houben and W. Proesmans leg.; leafy humus of a birch forest; XIV.2.34; HU - 1 spec.,

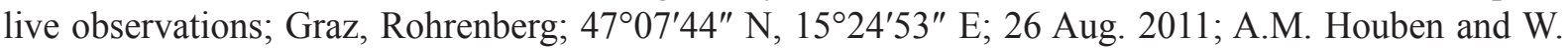
Proesmans leg.; between dead leaves - 2 specs, serially sectioned; Graz, Kanzelkügel; $47^{\circ} 06^{\prime} 49^{\prime \prime} \mathrm{N}$, 15²3'11" E; 26 Aug. 2011; leafy humus; XIV.2.35-XIV.2.36; HU • 1 spec., live observations; Weyer, Kreuzberg; 47 51'36" N, 14³9'09" E; 26 Aug. 2011; A.M. Houben and W. Proesmans leg.; humus of a mixed forest -4 specs, live observations, one of which serially sectioned; Weyer, Kreuzberg; 4751'29" N, 14³9'14" E; 26 Aug. 2011; A.M. Houben and W. Proesmans leg.; moss growing on a dead trunk; XIV.2.37; HU.

\section{Description and discussion}

The specimens from Austria are about $0.8 \mathrm{~mm}$ long and very dark due to their gut content (Fig. 3B). Habitus and internal organs are as described by Kolasa (1977), with the exception that protonephridiopores of one specimen (not drawn) are situated just anterior to the pharynx and not lateral to or slightly behind the pharynx as originally described. However, in most specimens, they are situated at $\pm 50 \%$ of the body (pp, 
Fig. 3A). Due to the small size of the specimens, it was not possible to make a thorough reconstruction of the reproductive structures from the sectioned specimens.

Although Ventrociliella romanae was originally placed within 'Protoplanellinae', it was recently listed as a taxon incertae sedis within Dalytyphloplanida (Van Steenkiste et al. 2010). Awaiting the inclusion of this taxon in molecular phylogenetic analyses, we for now keep this genus as incertae sedis, with probably a high affiliation to 'Protoplanellinae': Kolasa (1977) considered V. romanae closely related to the protoplanellin Bockia deses Reisinger, 1924 because of their similar habitus, the position of the male reproductive organ, the construction of the pharynx, and their limnoterrestrial lifestyle. Indeed, the only drawing ever published of $B$. deses (Reisinger 1954: fig. 10) closely resembles the drawing we constructed of a free-swimming specimen of V. romanae (Fig. 3B). Considering their similarity, and especially since the description of $B$. deses is based on a single specimen, a re-assessment of the validity of these species is warranted. As we found new material of $V$. romanae on the type locality of $B$. deses, we here present a detailed morphological comparison between both species.

Kolasa (1977) stated that $V$. romanae and B. deses differ due to the presence of (1) a real pharynx doliiformis, (2) the lack of adenal rhabdites, (3) the absence of a bursa, (4) the occurrence of ciliation all over the body, (5) the lack of a seminal receptacle, and (6) a sclerotised ejaculatory duct. However, the pharynx of $V$. romanae is strongly tilted forwards, which makes it possible to describe it as a pharynx doliiformis (1). Furthermore, in some of our specimens of $V$. romanae, adenal rhabdites are barely visible and may easily be overlooked (2). The bursa originally described by Kolasa (1977) was sometimes seen as a large genital atrium, a characteristic also mentioned in the description of $B$. deses (Reisinger

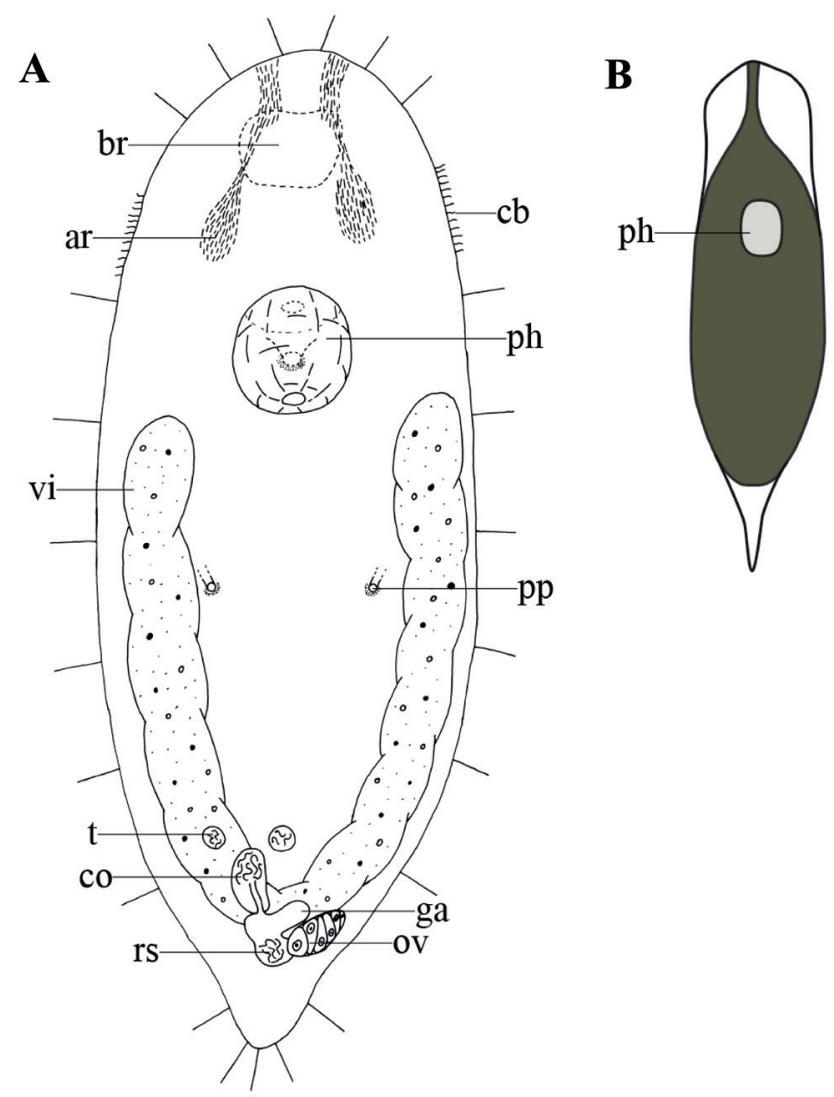

Fig. 3. Ventrociliella romanae Kolasa, 1977. A. Internal organisation of a live specimen. B. Habitus of a live specimen. 
1924) (3). Reisinger (1924) never made any remarks on body ciliation. Indeed, this is a rather subtle characteristic and may have easily been missed on a single specimen (4). As the seminal vesicle of $V$. romanae is merely an accumulation of sperm in the oviduct, it could be easily overlooked if it is not filled. Therefore, the absence of this vesicle in $B$. deses has little diagnostic value (5). The only clear difference between the two species may be that the ejaculatory duct of $B$. deses is slightly sclerotised, while it is muscular in $V$. romanae. However, considering their small size and the absence of sectioned material of $B$. deses, the reliability of this characteristic is also questionable (6). Finally, the typical, conspicuous, vacuolated epidermis of $V$. romanae was never mentioned for $B$. deses.

As all presumed differences are questionable to some degree, it is highly likely that $V$. romanae and $B$. deses belong to the same genus or perhaps are synonyms. In the latter case, $V$. romanae would become the junior synonym of $B$. deses. Resolving this possible synonymy is a challenging task, as specimens identified as either species are reported from the same (type) locality. A more exhaustive resampling effort on this sampling locality may provide more clarity: Microscopical study of a large sample may or may not reveal a consistent difference in the above-mentioned morphological traits, possibly demonstrating their diagnostic value. Sequencing morphologically vouchered representatives of both presumed species and subsequent molecular delineation methods may then provide further evidence for the validity of these taxa. However, with the data available today, Bockia deses is better considered a nomen dubium.

\section{Previously known distribution}

Forest soil near the stream Fosso Contesora in Tuscany, Italy (Kolasa 1977).

Subfamily 'Protoplanellinae' Reisinger, 1924

Genus Adenocerca Reisinger, 1924

Adenocerca minima Kolasa, 1981

Fig. 4

\section{Material examined}

AUSTRIA - 3 specs, studied alive, one of which whole mounted and a second one horizontally sectioned; south of Graz, between Glashütten and Trahütten; 46 49'46" N, 1506' $09^{\prime \prime}$ E; 23 Aug. 2011; A.M. Houben and W. Proesmans leg.; humid moss from a small stream in a pine forest; XIV.2.38 and XIV.3.18; HU.

\section{Description and discussion}

Specimens are about $0.6 \mathrm{~mm}$ long. Habitus and internal organisation correspond to the description of Kolasa (1981b). However, the original description, based on one specimen, mentions a much smaller animal $(0.3 \mathrm{~mm})$ (see Kolasa 1981b). Small dermal rhabdites are present all over the body. Protonephridiopores (Fig. 4A: pp) are situated lateral to the pharynx (Fig. 4A-B: ph). The two small testes (Fig. 4A-B: t) are situated caudally from the pharynx, at $65-70 \%$ of the body.

Adenocerca minima clearly differs from all other representatives of Adenocerca by the orientation of the spines of its copulatory organ (see Fig. 4C-F). Small spines are present in the distal half of the cirrus and at the distal end, where $6 \mu \mathrm{m}$ long, distally pointing, crescent-shaped spines form a crown (Fig. 4C: cs). Other species only possess small spines (A. clinopharynx Reisinger, 1924 and A. teshirogii) or have a different orientation of these spines, with the proximal spines being the biggest (A. bresslaui Reisinger, 1924). 


\section{Remarks}

Kolasa (1981b) mentioned seven crown spines while we only counted six. Both Kolasa's and our counts were made on a single specimen. Therefore, for the time being, we prefer to designate our specimens to the same species as Kolasa's (1981b).

\section{Previously known distribution}

In wet mosses on the banks of the stream Fosso Contesora, Italy (Kolasa 1981b).
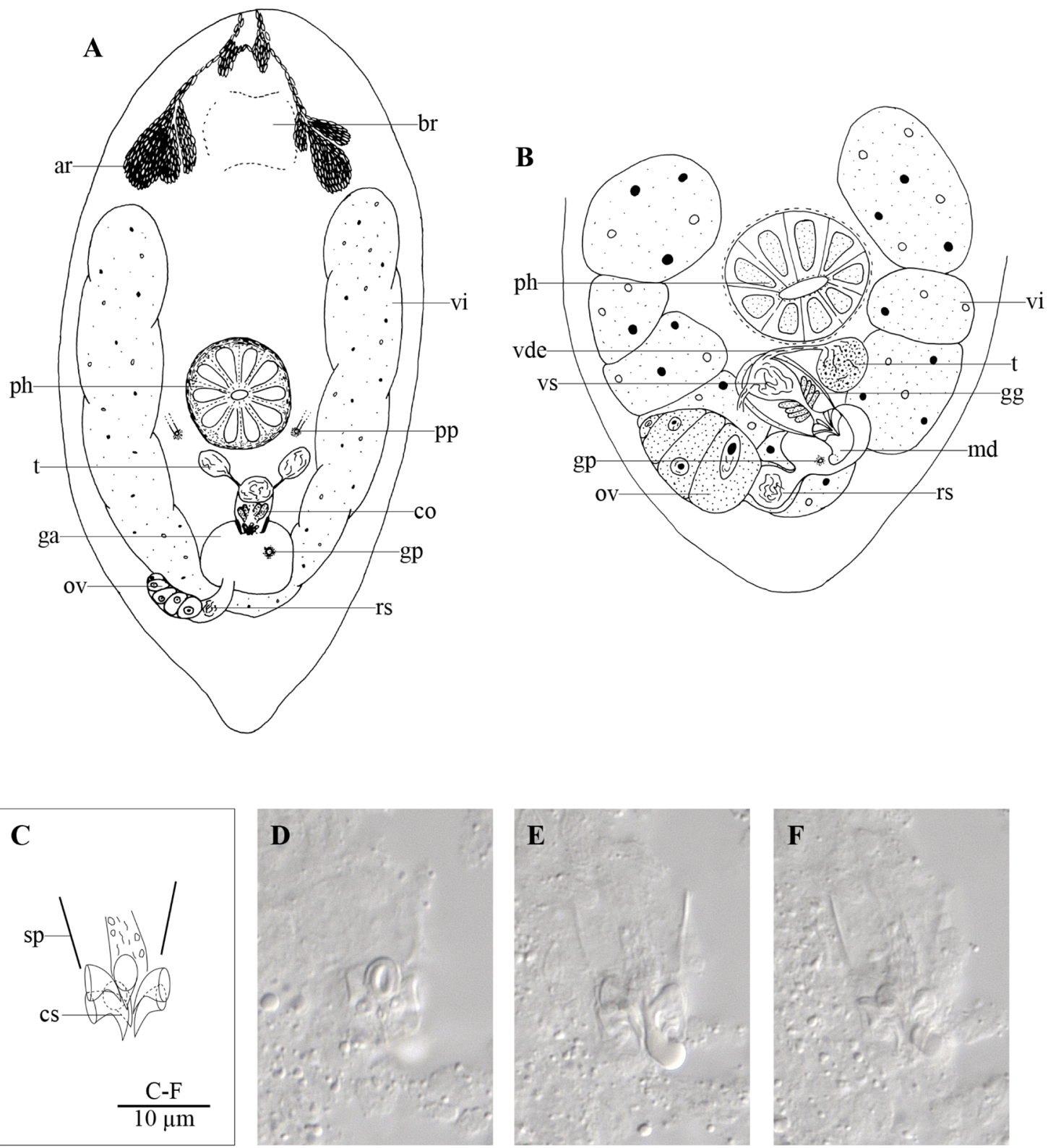

Fig. 4. Adenocerca minima Kolasa, 1981. A. Internal organisation of a live specimen. B. Reconstruction of reproductive organs based on horizontal sections. C-F. Male copulatory organ of the whole-mounted specimen (XIV.3.18). 
HOUBEN A.M. et al., Systematics of limnoterrestrial 'Typhloplanidae'

Genus Bryoplana Van Steenkiste, Davison \& Artois, 2010

\section{Type species}

Bryoplana xerophila Van Steenkiste, Davison \& Artois, 2010.

\section{Remark}

As Bryoplana belgica Houben, Proesmans \& Artois sp. nov. is only the second species to be described within the genus, we here provide a new, emended diagnosis for Bryoplana Van Steenkiste, Davison \& Artois, 2010, as well as the type species Bryoplana xerophila Van Steenkiste, Davison \& Artois, 2010. For further details, please refer to the discussion on B. belgica Houben, Proesmans \& Artois sp. nov. below.

\section{Diagnoses}

\section{Bryoplana}

Diagnosis amended after Van Steenkiste et al. 2010. Genus of 'Protoplanellinae' without dermal or adenal rhabdites. Eyes absent. Pharynx somewhat elongate, in anterior part of body and slanting obliquely forward. Paired testes near the caudal body end and ventrocaudal to the vitellaria. Simple muscular tube as copulatory organ. Bursa copulatrix absent.

\section{Bryoplana xerophila}

Species of Bryoplana with the body completely covered by cilia. Testes small, globular. Copulatory organ without any sclerotisation. Without seminal vesicle.

Bryoplana belgica Houben, Proesmans \& Artois sp. nov. urn:1sid:zoobank.org:act:1F08C372-CBAE-45E6-BE50-144752F3D44B

Fig. 5

\section{Diagnosis}

Species of Bryoplana with the ciliation reduced or completely lacking dorsally. Testes elongated, in the posterior body part, lateral to the copulatory organ. Copulatory organ with bent, sclerotised ejaculatory duct. Most proximal part of female duct forming a seminal receptacle.

\section{Etymology}

The epithet refers to the fact that the species was found in Belgium.

\section{Material examined}

\section{Holotype}

BELGIUM • 1 spec., studied alive and serially sectioned; Koksijde, Oostduinkerke, nature reserve 'De Zeebermduinen'; 51 $08^{\prime} 22^{\prime \prime}$ N, 02 $41^{\prime} 26^{\prime \prime}$ E; 30 Jul. 2011; A.M. Houben and W. Proesmans leg.; dry moss growing on dunes; KV.687; FMNH.

\section{Description}

The specimen is about $0.8 \mathrm{~mm}$ long. Both body ends are rounded (Fig. 5A-B). Free swimming specimens show a small tail. Adenal rhabdite glands (Fig. $5 \mathrm{~A}$ : ar) are situated in two groups at $\pm 25 \%$ of the body. Dermal rhabdites and protonephridiopores were not observed. The epidermis on the ventral body side is $4.5 \mu \mathrm{m}$ high and entirely covered with locomotory cilia, while on the dorsal body side it is $3.5 \mu \mathrm{m}$ high and ciliation is strongly reduced, even almost completely lacking. A slightly forward-slanted rosulate pharynx (Fig. 5A-B: ph) is located just rostral to the centre of the body. 
The gonopore (Fig. 5C-D: gp) is situated at $\pm 80 \%$ of the body and connected to a genital atrium (Fig. 5A, C-D: ga), which is lined with a high, nucleated epithelium and surrounded by muscles, the orientation of which could not be observed with certainty.

The elongated testes (Fig. $5 \mathrm{~A}, \mathrm{C}-\mathrm{D}$ : $\mathrm{t}$ ) lie at $\pm 70 \%$ of the body and ventrally to the paired vitellaria (Fig. 5A-D: vi). They gradually taper into the broad vasa deferentia (Fig. 5C: vde), which laterally enter the copulatory organ (Fig. 5A: co). Circular muscles surround the $34 \mu \mathrm{m}$ long copulatory organ, which includes an intracapsular seminal vesicle (Fig. 5C-E: vs) and a $22 \mu \mathrm{m}$ long, strongly sclerotised
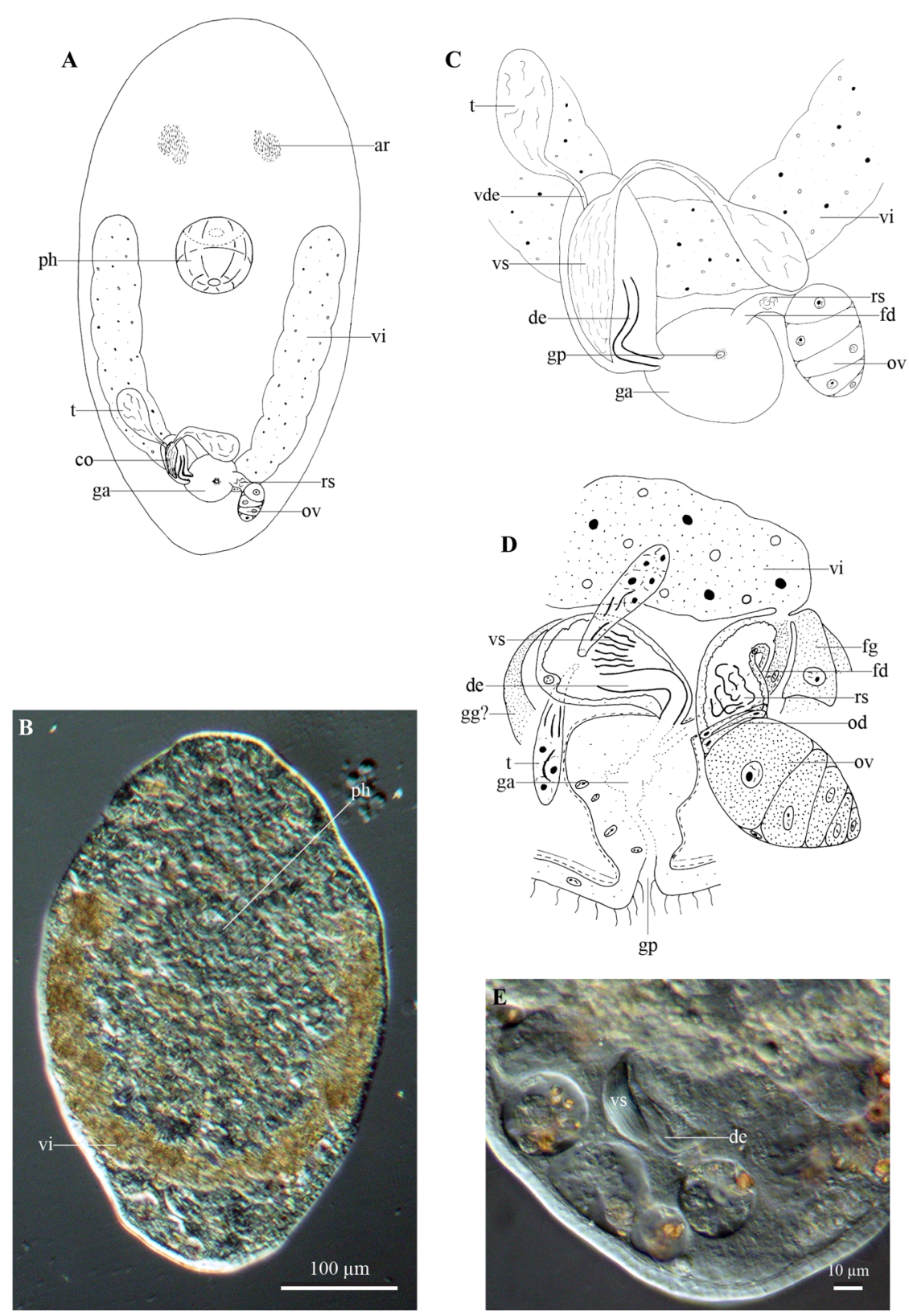

Fig. 5. Bryoplana belgica Houben, Proesmans \& Artois sp. nov. A. Internal organisation of a live specimen. B. Squash preparation of a live specimen. C. Organisation of the genital system of a live specimen. D. Reconstruction of reproductive organs based on sagittal sections of the holotype (KV.687). E. Detail of the genital system of the holotype (live photograph) (KV.687). 
ejaculatory duct (Fig. 5C-E: de). This ejaculatory duct is more or less straight at its proximal end and bends strongly $\left( \pm 100^{\circ}\right)$ at the distal end. Coarse-grained eosinophilic glands are situated ventrally to the copulatory organ. Although the entrance into the copulatory organ could not be seen, these glands probably represent the prostate glands (Fig. 5D: gg?).

The female duct (Fig. 5C-D: fd) is relatively long and lined with a nuclear epithelium. Proximally, it widens into a seminal receptacle (Fig. 5A, C-D: rs), which receives the short oviduct (Fig. 5D: od). The vitelloduct and female glands (Fig. 5D: fg) open into this female duct at the place where it connects to the seminal receptacle.

\section{Discussion}

The new species can readily be placed within 'Typhloplanidae' because it possesses all diagnostic features: a pharynx rosulatus, a single ovary, paired testes, and a single genital opening. Furthermore, the ventral position of the testes relative to the vitellaria indicates this species should be placed in 'Protoplanellinae', 'Rhynchomesostominae' Bresslau, 1933 or 'Typhloplaninae' Graff, 1905. However, the species' general habitus and internal organisation differ markedly from the situation in the latter two subtaxa, and we therefore designate this species to 'Protoplanellinae'.

Most representatives of 'Protoplanellinae' have the pharynx situated in the midbody or posterior body half. Only select species have a pharynx in the anterior half of the body, these belong to Achrochordonoposthia Reisinger, 1924; Bockia Reisinger, 1924; Bryoplana; Microcalyptorhynchus Kepner \& Ruebush, 1935, Prorhynchella Ruebush, 1939; and Protopharyngiellona Schwank, 1980. Some of these genera show very typical features: presence of a proboscis (Microcalyptorhynchus), presence of ciliated pits in the anterior body half (Prorhynchella), or the fact that the proboscis is of the doliiformis-type (Bockia). Lack of these features in our species indicates that it cannot be allocated to any of these genera. One of the most eye-catching features of $B$. belgica Houben, Proesmans \& Artois sp. nov. is the lack of a bursa copulatrix, which in the remaining taxa is only the case for Bryoplana. We hence allocate our specimens to the latter genus, to which it indeed shows much resemblance.

Bryoplana belgica Houben, Proesmans \& Artois sp. nov. differs from Bryoplana xerophila by the presence of a sclerotised, curved ejaculatory duct, the presence of a seminal receptacle in the female system, and the fact that the dorsal body ciliation is very much reduced, or even lacking. The latter feature was also mentioned by Kolasa (1977) for Ventrociliella romanae, which he suggested to be an adaptation to limnoterrestrial habitats. However, in all other typical limnoterrestrial taxa, even in B. xerophila, the dorsal ciliation is present. Both species of Bryoplana were recovered from dried out moss - B. xerophila in the USA and B. belgica Houben, Proesmans \& Artois sp. nov. in Western Europe - but indeed differ markedly in the extent of the dorsal body ciliation, undermining Kolasa's (1977) hypothesis. The presence/absence of a seminal receptacle in the female system as a distinguishing character should be used with care at this moment. Indeed, the seminal receptacle in B. belgica Houben, Proesmans \& Artois sp. nov. is simply a swelling of the female duct, and not a separate organ. As such, the absence of this structure in B. xerophila may be due to the specimens of Van Steenkiste et al. (2010) not having mated yet. However, as Van Steenkiste et al. (2010) investigated several live specimens and twelve serial sections, this seems unlikely. Regardless, the differences in body ciliation and construction of the copulatory organ proper clearly distinguish both species. 
Genus Chorizogynopora Reisinger, 1924

Chorizogynopora italica Kolasa, 1981

Fig. 6

\section{Material examined}

GERMANY • 1 spec., studied alive; Schlitz-Breitenbach; 50³9'31" N, 09³7'46" E; 9 Aug. 2011; A.M. Houben and W. Proesmans leg.; mossy rocks 22 specs, studied alive; Wasserküppe; $50^{\circ} 29^{\prime} 27^{\prime \prime}$ N, 09 56'52" E; 10 Aug. 2011; A.M. Houben and W. Proesmans leg.; moss (Fontinalis sp.) near the source of the river Fulda $\bullet 2$ specs, studied alive and serially sectioned; same collection data as for preceding; $50^{\circ} 29^{\prime} 21^{\prime \prime} \mathrm{N}, 09^{\circ} 56^{\prime} 57^{\prime \prime} \mathrm{E}$; XIV.2.39-XIV.2.40; HU • 4 specs, studied alive, one of which serially sectioned; Graswiesenbach, Vogelsberg; dark moss in fast-flowing water, on rocks in and just above the water; 50³2'08" N, 09¹2'00" E; 10 Aug. 2011; A.M. Houben and W. Proesmans leg.; XIV.2.41; HU.

\section{Description and discussion}

Habitus and internal organisation indicate that these specimens belong to Chorizogynopora italica. Although this species was properly described and illustrated by Kolasa (1981b), there are some small differences between our specimens and the original description. Therefore, we here provide a reconstruction of the genital system of our specimens.

The examined specimens are $0.7-0.8 \mathrm{~mm}$ long and very translucent. The body shape is blunt to rounded anteriorly and usually round with sometimes a small tail posteriorly (Fig. 6A). Adenal rhabdite glands (Fig. 6A: ar) are situated at $25 \%$ of the body and give rise to two tracts that extend to the anterior body tip, partly anastomosing at their distal end. Dermal rhabdites were not observed. Paired protonephridiopores lie posterior to the rosulate pharynx (Fig. 6A: ph), which lies just behind the centre of the body.

The gonopore (Fig. $6 \mathrm{~A}-\mathrm{C}$ : gp) is situated at $\pm 80 \%$ of the body and connected to a genital atrium (Fig. 6A-C: ga). The latter is surrounded by an inner circular and outer longitudinal muscle layer.

The paired, large testes (Fig. 6A: t) lie just anterior to the pharynx and ventral to the paired vitellaria (Fig. 6A-B: vi). Both broad vasa deferentia (Fig. 6B-C: vde) narrow gradually and fuse just before entering the copulatory bulbus. Two layers of spiral muscles surround the $52 \mu \mathrm{m}$ long, oval-shaped copulatory organ (Fig. 6A: co), which comprises an intracapsular seminal vesicle (Fig. 6B-C: vs) and a slightly sclerotised ejaculatory duct (Fig. 6B-C: de). The duct is surrounded by circular muscles (see Fig. 6B). Large, coarse-grained, extracapsular eosinophilic glands (Fig. 6A-C: gg) enter the copulatory organ at the proximal end. A short male duct (Fig. 6C: md) connects the copulatory organ to the genital atrium. A small muscular bursa (Fig. $6 \mathrm{~A}-\mathrm{C}$ : bu) containing sperm and prostate secretion is directly connected to the genital atrium. Its shape varies greatly between individuals. In some specimens, it is very narrow and elongate, while in others it is more egg-shaped. In some live specimens, groups of small spines were observed at both the proximal and distal end of the bursa, with the larger ones found at the distal end. Also associated with the bursa are some strong retractor muscles (Fig. 6C: rm), which are anchored to the dorsal epidermis.

The vitellaria (Fig. 6A-B: vi) extend at both sides of the body, from just behind the rhabdite glands to the level of the gonopore. The female duct (Fig. 6C: fd) is relatively broad, surrounded by muscles and lined with a high, nuclear epithelium. It receives the oviduct (Fig. 6C: od), a long seminal receptacle (Fig. 6A-C: rs), and the common vitelloduct (Fig. 6C: vd) proximally. A small muscular evagination of the atrium, which might serve as a uterus (Fig. 6C: ut), is present. 
The testes of our specimens are relatively larger, and the uterus relatively smaller than those described by Kolasa (1981b). Furthermore, Kolasa (1981b) observed tail glands, which we did not observe in our specimens. Despite these small differences the specimens studied are identified as C. italica due to their typical body shape, the presence of an elongated seminal receptacle, and the detailed structure of both the copulatory organ and the bursa.

Kolasa (1981b) described substantial differences between C. italica and C. paradoxa Reisinger, 1924, which is the only other species of Chorizogynopora Reisinger, 1924. Nevertheless, he distinctly mentioned these differences are probably not significant at the genus level. For a detailed discussion, the reader is referred to Kolasa (1981b).
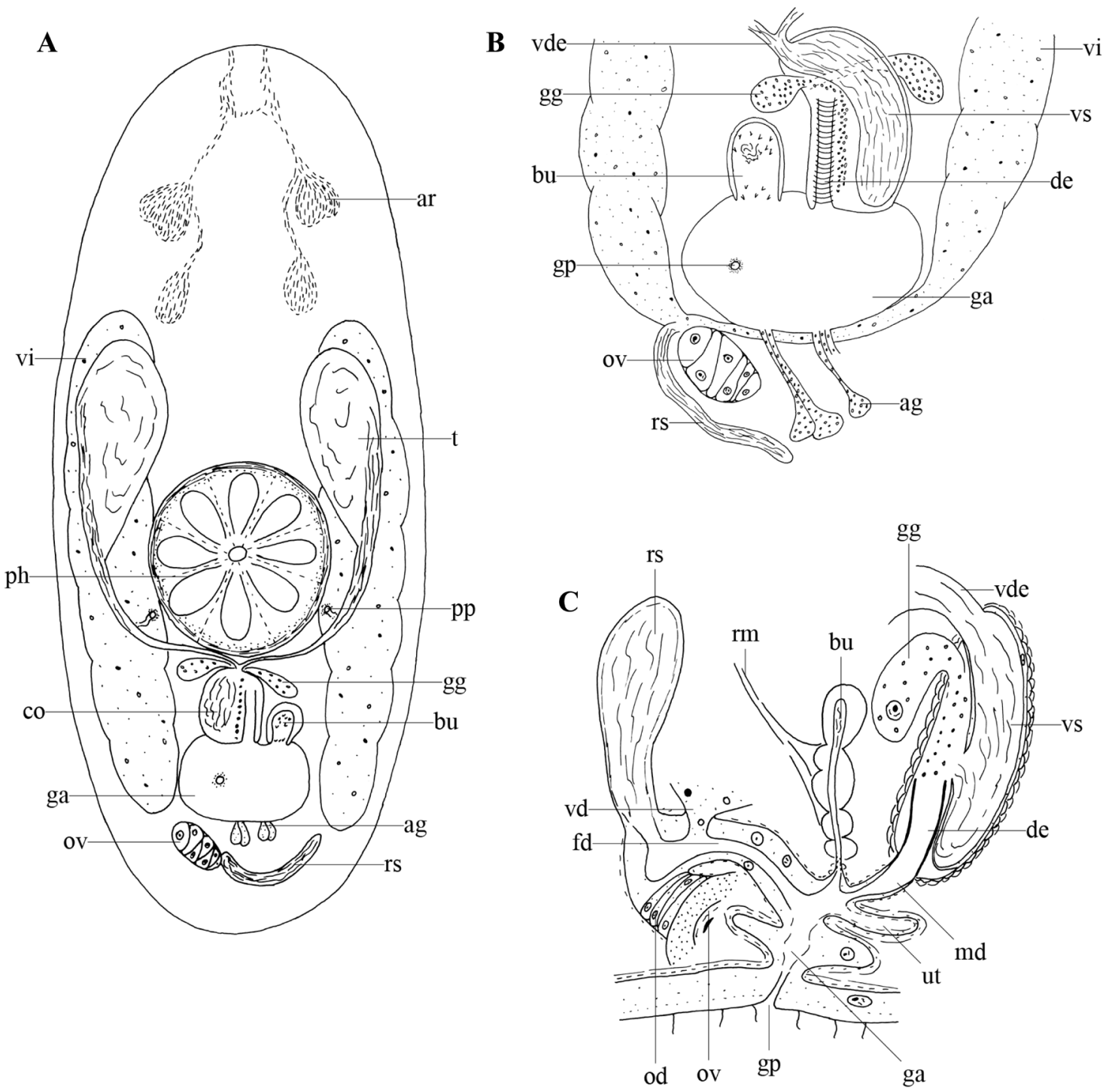

Fig. 6. Chorizogynopora italica Kolasa, 1981. A. Internal organisation of a live specimen. B. Organisation of the genital system of a live specimen. C. Reconstruction of reproductive organs based on sagittal sections. 


\section{Remarks}

Specimens with one egg were observed. It was not possible to ascertain whether it was carried in the atrium or the uterus. Nematodes were observed in the gut of specimens.

\section{Previously known distribution}

Tuscany, Italy, in heavily moistened mosses growing in the stream Fosso Contesora (Kolasa 1981b).

Genus Hoplopera Reisinger, 1924

Hoplopera isis Houben, Proesmans \& Artois sp. nov. urn:lsid:zoobank.org:act:4DA3359A-D279-4286-B7B0-822382D258F7

Fig. $7 \mathrm{~A}-\mathrm{C}$

\section{Diagnosis}

Dark species of Hoplopera, about $0.8 \mathrm{~mm}$ long with inconspicuous tail glands. Dermal rhabdites small, adenal rhabdites in two tracks. Atrial glands present. Spindle-shaped testes. Copulatory organ $20 \mu \mathrm{m}$ long, without sclerotised structures. Bipartite bursa with sclerotised structure containing two groups of parallel, vertical rods, separated from each other by vertical bars, as a whole resembling a fish pot. Female duct forming a seminal receptacle.

\section{Etymology}

The species epithet is dedicated to Isis Houben, first daughter of the first author (A.M. Houben).

\section{Material examined}

\section{Holotype}

AUSTRIA 1 spec., studied alive and horizontally sectioned; south of Graz, between Glashütten and Trahütten; 4649'46" N, 1506'09" E; 23 Aug. 2011; A.M. Houben and W. Proesmans leg.; moss growing in a small stream in a pine forest; KV.688; FMNH.

\section{Paratypes}

AUSTRIA -5 specs, studied alive, one of which whole mounted; same collection data as for holotype; paratype no. 822; HU.

\section{Description}

Specimens are about $0.7-0.9 \mathrm{~mm}$ long. The body is rounded anteriorly and possesses a small tail provided with small, inconspicuous tail glands (Fig. 7C: tg). Rostrally, sharply pointed adenal rhabdites (Fig. 7B: ar) are arranged in two groups. Very small dermal rhabdites occur all over the body. The paired protonephridiopores (Fig. 7A: pp) lie posterior and lateral to the mouth. The rosulate pharynx is located just behind the middle of the body (Fig. 7A: ph).

The gonopore (Fig. 7B-C: gp) is situated at $\pm 80 \%$ of the body and connected to a genital atrium (Fig. 7A-C: ga) that is lined with a high epithelium and surrounded by muscles of uncertain orientation. At its posterior side, the genital atrium receives a large group of eosinophilic glands (Fig. 7A-C: ag).

Two small, spindle-shaped testes (Fig. 7A: t) lie in front of the pharynx (Fig. 7A: ph) and ventral to the paired vitellaria (Fig. 7A, C: vi). In some specimens, one testis seems bigger than the other one. The paired vasa deferentia (Fig. 7B-C: vde) enter the egg-shaped copulatory organ laterally. Two layers of spiral muscles surround the $24 \mu \mathrm{m}$ long copulatory organ (Fig. 7A: co), which bears an intracapsular seminal vesicle (Fig. 7B-C: vs) and an ejaculatory duct (Fig. 7B-C: de). Coarse-grained intra- (Fig. 7B- 


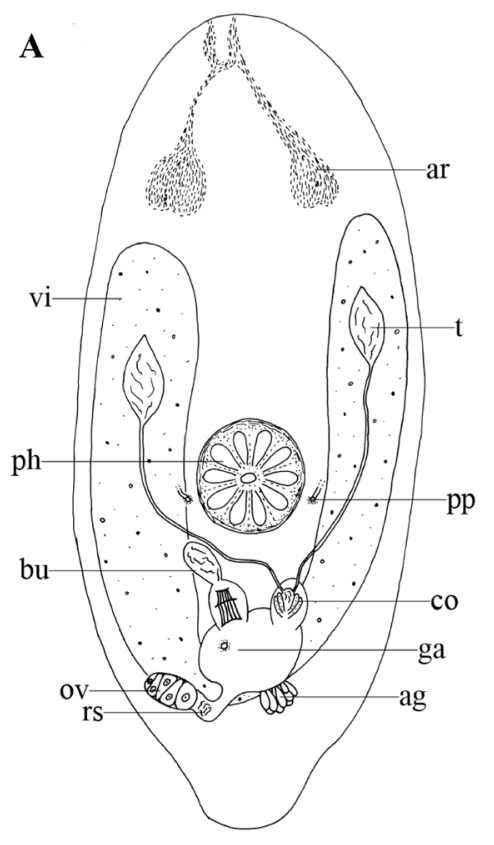

B
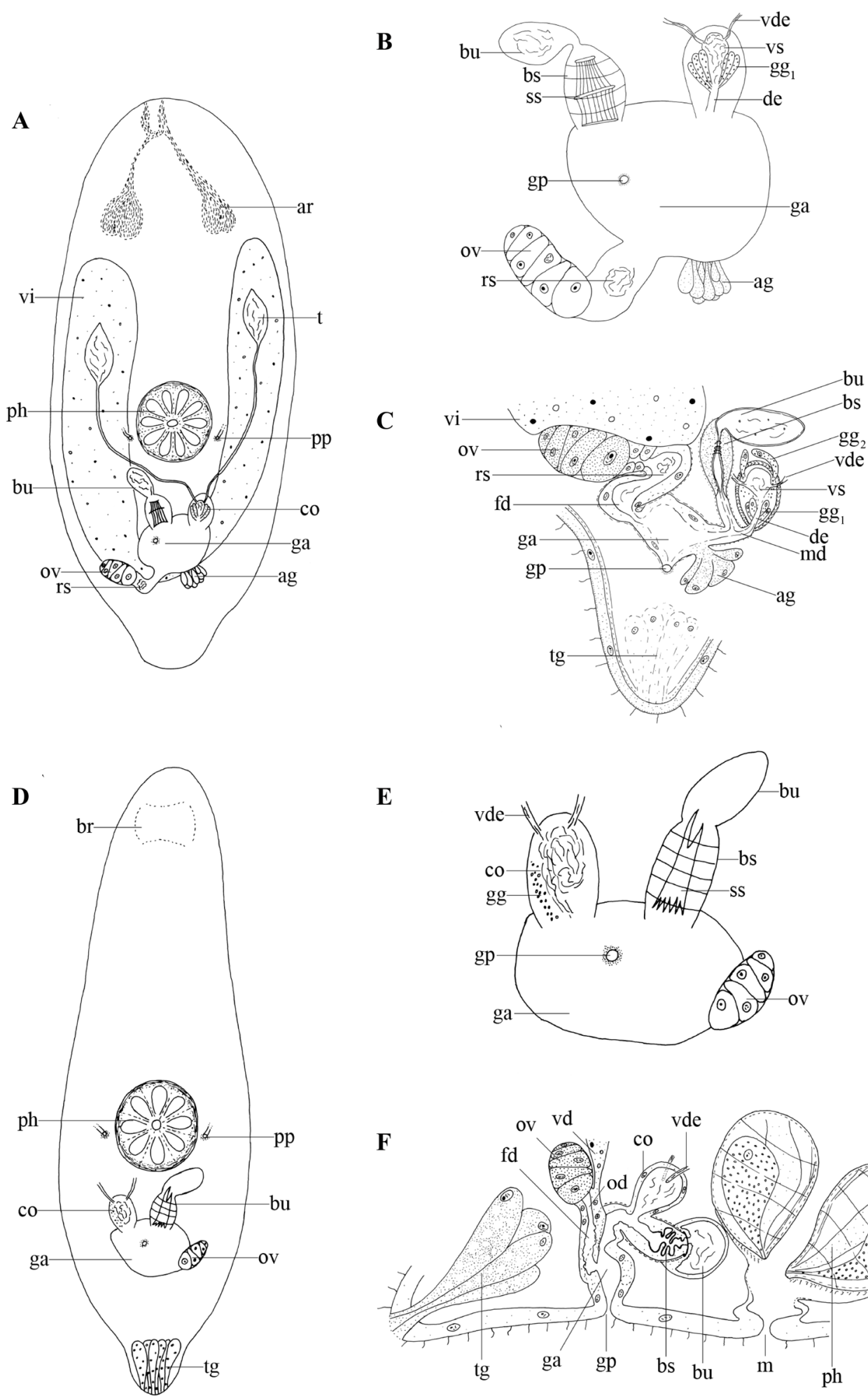

$\mathbf{E}$
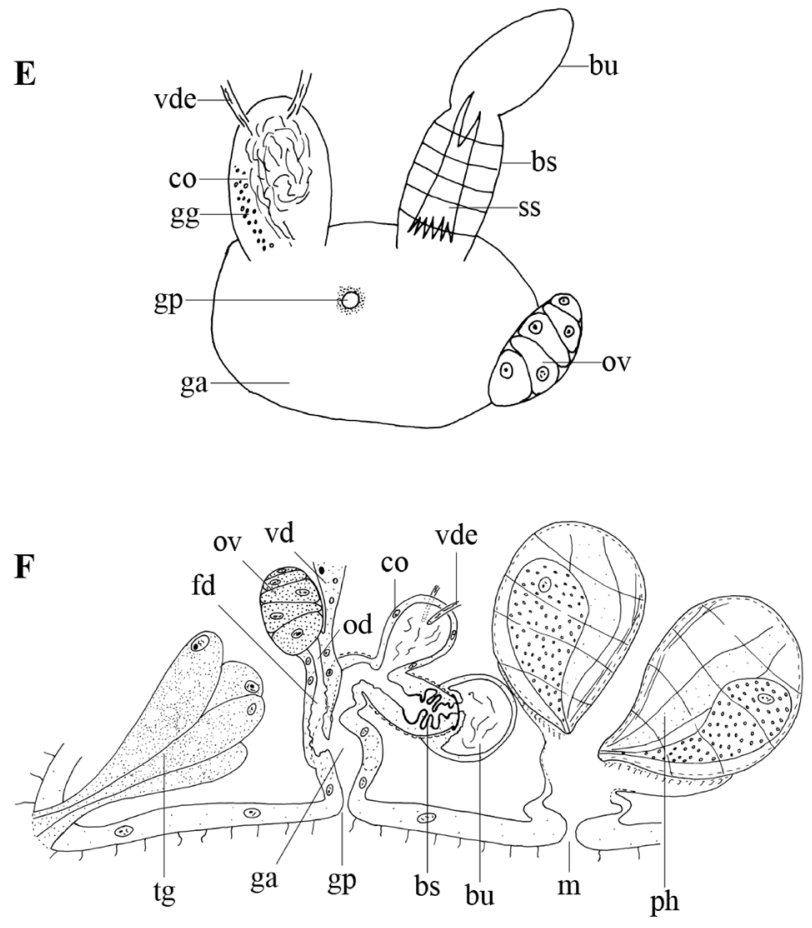

Fig. 7. Two species of Hoplopera Reisinger, 1924. A-C. Hoplopera isis Houben, Proesmans \& Artois sp. nov. A. Internal organisation of a live specimen. B. Organisation of the genital system of a live specimen. C. Reconstruction of reproductive organs based on horizontal sections. D-F. Hoplopera opaca Reisinger, 1924. D. Internal organisation of a live specimen. E. Organisation of the genital system of a live specimen. F. Reconstruction of reproductive organs based on sagittal sections. 
C: gg1) and extracapsular (Fig. 7C: gg2) eosinophilic glands are associated with the copulatory organ. The relatively long male duct (Fig. 7C: md) receives the bursa (Fig. 7A-C: bu) before entering the genital atrium (Fig. 7A-C: ga). This bipartite bursa consists of an $18 \mu \mathrm{m}$ long, thin-walled proximal part containing sperm and a $22 \mu \mathrm{m}$ long distal part, which could be considered the bursal stalk (Fig. 7B-C: bs). This stalk is surrounded by circular muscles and contains a sclerotised structure (Fig. 7B: ss) that resembles the structure of a fish pot. It consists of vertical rods that are divided into two groups by a horizontal bar. The proximal and distal part are also delimited by a horizontal bar. As a whole, this bursal stalk is wrapped in a loose matrix surrounded by circular muscles.

The vitellaria (Fig. 7A, C: vi) extend from the anterior third of the body to the posterior end where they meet. The oviduct broadens and becomes a seminal receptacle (Fig. 7A-C: rs), which further becomes a long female duct (Fig. 7C: fd), lined with a high, nucleated epithelium and surrounded by muscles. The vitelloduct was not observed with certainty, although it is probably an unpaired one that meets the oviduct.

\section{Discussion}

See the general discussion on the genus Hoplopera.

\section{Remarks}

The hard parts and copulatory structures are not visible on the whole-mounted specimen. Therefore, we designate a serially sectioned specimen as holotype.

\section{Hoplopera opaca Reisinger, 1924}

Fig. 7D-F

\section{Material examined}

AUSTRIA - 1 spec., studied alive and sagittally sectioned; Hohe Rannach near Graz; 47 $09^{\prime} 53^{\prime \prime} \mathrm{N}$, $15^{\circ} 24^{\prime} 50^{\prime \prime}$ E; 26 Aug. 2011; A.M. Houben and W. Proesmans leg.; leafy humus of a birch forest; XIV.2.42; HU.

\section{Description}

Our specimen is about $1 \mathrm{~mm}$ long and very dark. The anterior end is rounded, with the posterior end showing a distinct tail with pronounced eosinophilic tail glands (Fig. 7D: tg). Small dermal rhabdites occur all over the body. Adenal rhabdites are rather inconspicuous and only visible on the sectioned specimen. Paired protonephridiopores (Fig. 7D: pp) open posterior to the mouth. A rosulate pharynx (Fig. 7D: ph) is positioned at $\pm 75 \%$ of the body.

The gonopore (Fig. 7E-F: gp) is situated at $\pm 80 \%$ of the body and connected to a genital atrium (Fig. $7 \mathrm{D}-$ F: ga), which is surrounded by muscles and lined with a high epithelium.

The vasa deferentia (Fig. 7F: vde) enter the copulatory organ (Fig. 7D-F: co) separately. This copulatory organ is a $20 \mu \mathrm{m}$ long, oval structure surrounded by muscles of uncertain orientation. It contains sperm in its proximal part, which probably serves as a seminal vesicle. An ejaculatory duct was not observed. Intracapsular prostate glands (Fig. 7E: gg) were observed on live specimens. The male duct is surrounded by circular muscles. The bipartite bursa (Fig. 7D-F: bu) bears a thin-walled, proximal part containing sperm and a long distal part, the bursal stalk (Fig. 7E-F: bs). This stalk is surrounded by circular muscles and contains a sclerotised structure (Fig. 7E: ss). It seems to consist of several vertical bars, which are fused in the distal part. 
The vitellaria were still developing in the studied specimen, but already reach up to $\pm 33 \%$ of the body. The female duct (Fig. 7F: fd) connects the oviduct (Fig. 7F: od) and vitelloduct (Fig. 7F: vd) to the genital atrium.

\section{Discussion}

See the general discussion on the genus Hoplopera.

\section{Previously known distribution}

Near Graz, Austria, in moist forest soils (Reisinger 1924).

\section{General discussion on Hoplopera}

All species of Hoplopera are characterised by a combination of features: pharynx situated in the caudal body half, presence of dermal rhabdites and adenal rhabdites, the latter organised in rostral tracks (i.e., Stäbchenstaßen), presence of tail glands, lack of a stylet, and the presence of a bursa copulatrix (see Van Steenkiste et al. 2010). This combination of features is also shown by Rhomboplanilla bryophila Schwank, 1980. However, species of Hoplopera all have a sclerotised structure in the bursa copulatrix, which is absent in R. bryophila.

Species of Hoplopera either occur in limnoterrestrial environments (H. isis Houben, Proesmans \& Artois sp. nov.; H. macropharynx Reisinger, 1924; H. maculata Reisinger, 1924; and H. opaca), or in marine to brackish habitats (H. littoralis Karling, 1957 and H. pusilla Ehlers, 1974). However, the marine origin of $H$. littoralis and $H$. pusilla has been questioned. Based on its sampling locality, Karling 1957 and Ax 2008 suggested that $H$. littoralis might as well be a limnoterrestrial species. H. pusilla was found in the supratidal of salty meadows with salinity below $10 \%$ and was therefore deemed brackish instead of limnoterrestrial (Armonies 1987).

All limnoterrestrial species possess a bipartite bursa, with the distal part (probably the bursal stalk) containing a sclerotised structure, while the bursa of the 'marine' animals consists of only one part. Furthermore, the vasa deferentia of the limnoterrestrial species enter the copulatory organ separately (Reisinger 1924), while they fuse just before entering the copulatory organ in H. littoralis and H. pusilla (Karling 1957; Ehlers 1974). Both the ecological and morphological differences suggest that Hoplopera may as well be split into two genera. Awaiting a thorough cladistic analysis, however, we prefer to maintain the taxon Hoplopera containing both limnoterrestrial and 'marine' animals.

The limnoterrestrial species of Hoplopera are most easily distinguished from each other by the shape of the sclerotised structure in the bursa. The fish pot-shaped sclerotic structure as seen in Hoplopera isis Houben, Proesmans \& Artois sp. nov. is unique within the genus. In the other three limnoterrestrial species, this structure consists of 6-8 bars proximally connected to a ring (H. macropharynx), 4 (rarely 5) elongated, spoon-shaped structures accompanied with two longitudinal plates (H. maculata) or 6-10 longitudinal bars with broadened distal ends and small protrusions towards the genital atrium (H. opaca) (Reisinger 1924). None of these species possesses the three horizontal bars present in $H$. isis Houben, Proesmans \& Artois sp. nov.

Apart from the above-mentioned differences, H. isis Houben, Proesmans \& Artois sp. nov. can also be distinguished from $H$. opaca and $H$. macropharynx by the presence of a seminal receptacle, a feature it shares with $H$. maculata. H. opaca has pronounced tail glands, while the tail glands of $H$. isis Houben, Proesmans \& Artois sp. nov. are small and inconspicuous. H. macropharynx has a conspicuous, large, and oval pharynx, which is unique among the species discussed. H. maculata is the largest of all limnoterrestrial species of Hoplopera $(1.5 \mathrm{~mm}$ vs. at most $1 \mathrm{~mm}$ for the other three species) and has typical parenchymal refracting spots (for details, see Reisinger 1924). 
Genus Krumbachia Reisinger, 1924

Krumbachia subterranea Reisinger, 1933

Fig. $8 \mathrm{~A}-\mathrm{C}$

\section{Material examined}

Neotype

GERMANY • 1 spec., studied alive and sagittally sectioned; Hessen; 50 46'30" N, 09³0'18' E; 9 Aug. 2011; A.M. Houben and W. Proesmans leg.; submersed meadow at the banks of the Breitenbach creek; neotype no. 823; HU.

\section{Reference material}

GERMANY • 1 spec., live observations; same collection data as for neotype.

\section{Description}

The examined specimens are around $2.5 \mathrm{~mm}$ long. The body is slender with a somewhat pointy anterior end and rounded posteriorly (see Fig. 8A). Adenal rhabdite glands occur just behind the brain (Fig. 8A: ar). Paired protonephridiopores (pp) are positioned ventrally, very near to the mouth (Fig. 8A: pp). A rosulate pharynx (Fig. 8A: ph) is situated just behind the centre of the body.

The gonopore (Fig. $8 \mathrm{~A}-\mathrm{C}$ : gp) is located at $\pm 75 \%$ of the body and connected to the gonoduct (Fig. $8 \mathrm{~B}-$ $\mathrm{C}$ : gd). The gonoduct is surrounded by an inner circular and outer longitudinal muscle layer, and lined with a ciliated, nuclear epithelium resembling the epidermis. The genital atrium (Fig. 8A-C: ga) is surrounded by a similar musculature and lined with a high, nucleated epithelium. On both lateral sides of the genital atrium, a group of proliferating cells (Fig. 8C: pc) is found. A large group of eosinophilic glands is situated posterior to the genital atrium and probably enters this atrium anteriorly (not drawn on the reconstruction).

The large, egg-shaped testes (Fig. 8A: t) lie anterior to the pharynx and ventral to the vitellaria (Fig. 8AB: vi). Paired vasa deferentia unite to form a single vas deferens (Fig. 8A-C: vde) just before entering the copulatory bulbus (Fig. 8A: co). Two layers of spiral muscles surround the long, curved copulatory organ, which bends up to $80^{\circ}$ towards its distal end. The copulatory organ bears an intracapsular seminal vesicle (Fig. 8B-C: vs) and a strongly sclerotised ejaculatory duct (Fig. 8B-C: de). Several coarsegrained, extracapsular eosinophilic glands (Fig. 8A-C: gg) enter the copulatory organ at the proximal end. Their secretion is lightly basophilic when entering the copulatory organ, however, it becomes strongly eosinophilic in the ejaculatory duct. A cone-shaped bursa (Fig. 8A-C: bu), surrounded by strong inner circular and outer longitudinal muscles, lies next to the copulatory organ and opens into the genital atrium.

The vitellaria extend from the region of the rhabdite glands to the posterior end (Fig. 8A: vi). The vitelloducts (Fig. 8C: vd) fuse just before opening into the female duct (Fig. 8C: fd). Furthermore, this duct is surrounded by a layer of circular muscles and receives the oviduct, a seminal receptacle (Fig. 8A-C: rs), and the female glands (Fig. 8C: fg). The seminal receptacle is provided with a short stalk, which also is surrounded by circular muscles.

\section{Discussion}

See the general discussion on the genus Krumbachia Reisinger, 1924. 

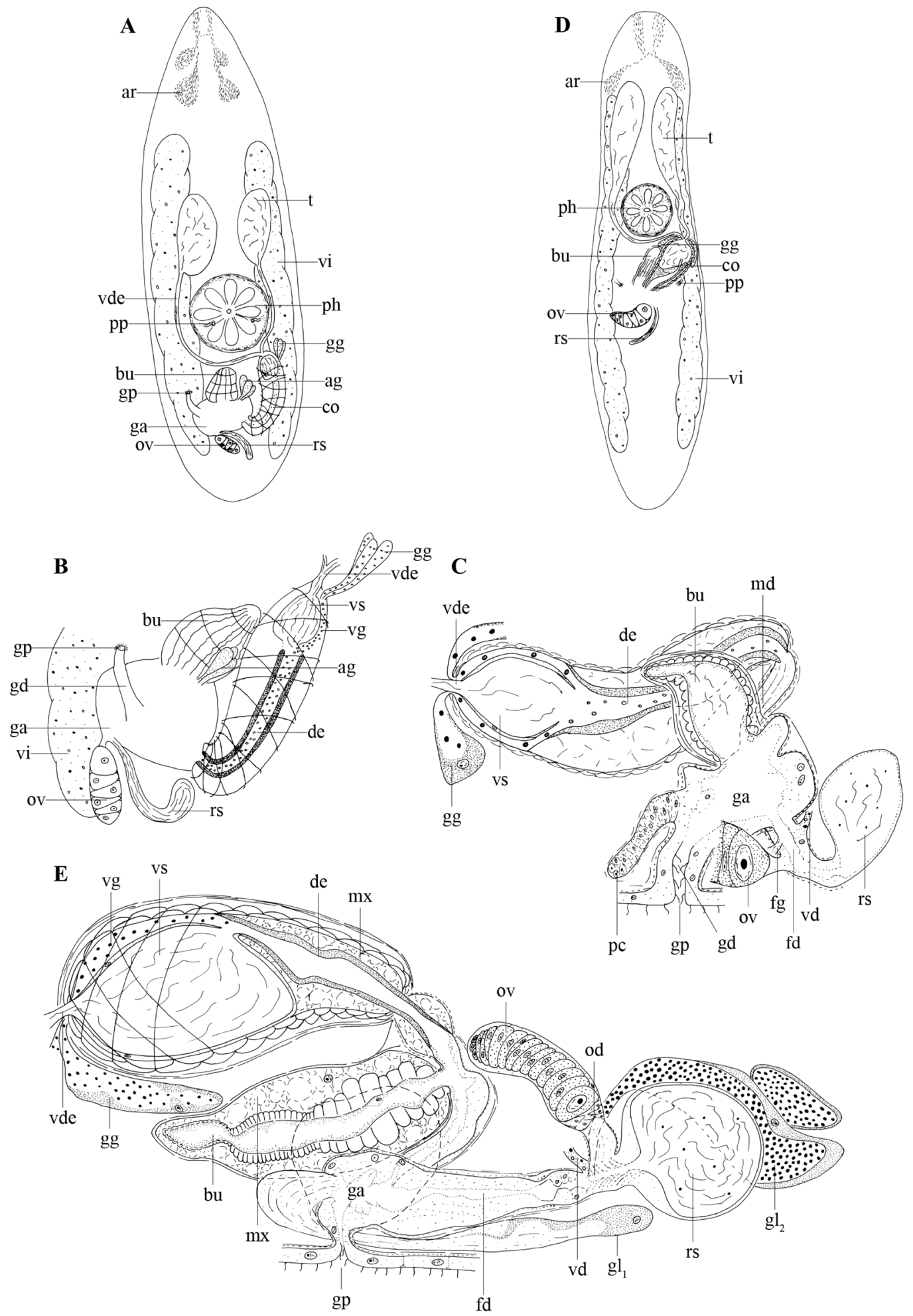

Fig. 8. Two species of Krumbachia Reisinger, 1924. A-C. Krumbachia subterranea Reisinger, 1933. A. Internal organisation of a live specimen. B. Organisation of the genital system of a live specimen. C. Reconstruction of reproductive organs based on sagittal sections of the neotype (neotype no. 823). D-E. Krumbachia virginiana (Kepner \& Carter, 1931) Ruebush, 1938. D. Internal organisation of a live specimen. E. Reconstruction of reproductive organs based on sagittal sections. 


\section{Previously known distribution}

Ruhr, Germany (Reisinger 1933), riparian forest near Schlitz, Germany (Schwank 1981). Common species in Europe (Lanfranchi \& Papi 1978).

Krumbachia virginiana (Kepner \& Carter, 1931) Ruebush, 1938

Fig. 8D-E

Olisthanella virginiana Kepner \& Carter, 1931.

Olisthanella virginiana - Senn 1935: 47-50. — Vandel 1937: 526. — Birstein 1991: 108.

\section{Material examined}

CANADA $\bullet 6$ specs, studied alive, one of which horizontally sectioned and the rest of which sagittally sectioned; Ontario, Dundas Valley Conservation Area; 4314'20" N, 7959'17" W; 6 May 2009; Niels Van Steenkiste leg.; submersed roots in a puddle of mud in a forest; XIV.2.43-XIV.2.48; HU.

\section{Description}

Specimens are very dark and around $3 \mathrm{~mm}$ long. The body is constricted at $\pm 30 \%$ and has a rounded anterior and posterior end (Fig. 8D). At $\pm 65 \%$ the body is at its widest. Rostrally, rhabdite glands (Fig. 8D: ar) are present and arranged in two groups. Dermal rhabdites are lacking. Protonephridiopores (Fig. 8D: pp) are positioned just behind the pharynx (Fig. 8D: ph), which is situated just before the body middle $( \pm 45 \%)$.

The gonopore (Fig. $8 \mathrm{E}$ : gp) is situated at $\pm 50 \%$ of the body and connected to a genital atrium (Fig. $8 \mathrm{E}$ : ga). The genital atrium is surrounded by an inner circular and outer longitudinal muscle layer and lined with a high, nucleated epithelium that is somewhat ruffled. Moreover, some fine-grained eosinophilic glands (Fig. 8E: g11) are situated posterior to the atrium and open anteriorly into the genital atrium.

The large, elongated, paired testes (Fig. 8D: t) lie anterior to the pharynx and ventral to the paired vitellaria (Fig. 8D: vi). The paired vasa deferentia (Fig. 8E: vde) fuse just before entering the copulatory bulbus (Fig. 8D: co). Two layers of spiral muscles and a third, weaker, outer longitudinal muscle layer surround the 240-320 $\mu \mathrm{m}$ long, slightly bent copulatory organ (see Fig. 8E). This organ bears an intracapsular seminal vesicle (Fig. 8E: vs) and a $215-250 \mu \mathrm{m}$ long, slightly bent, ejaculatory duct (Fig. 8E: de) with a thick, sclerotised layer $(5-6 \mu \mathrm{m})$. The entire ejaculatory duct is surrounded by a loose matrix (Fig. $8 \mathrm{E}$ : $\mathrm{mx}$ ) and at the proximal end, it shows a constriction. Large, coarse-grained, extracapsular basophilic glands (Fig. 8D-E: gg) are associated with the copulatory organ. A 200-260 $\mu \mathrm{m}$ long bursa (Fig. 8D$\mathrm{E}: \mathrm{bu}$ ) is situated next to the copulatory organ. This bursa is a muscular, elongated sack with a clear constriction at $20 \%$ of its length from the proximal tip (see Fig. 8E), dividing it into a proximal and distal part. Both parts are lined with a very thin epithelium, which is lacking at some places. The proximal part is surrounded by two weak layers of diagonal muscles. In the distal part, these muscles divide into a strong outer circular and weaker inner longitudinal layer. This entire structure is surrounded by a matrix (Fig. 8E: $\mathrm{mx}$ ) and an additional strong layer of longitudinal muscles.

The vitellaria (Fig. 8D: vi) extend from the region of the rhabdite glands to the almost posterior end. The vitelloducts (Fig. 8E: vd) fuse just before opening into the female duct (Fig. 8E: fd). At this place, the female duct also receives the oviduct (Fig. 8E: od), a large globular seminal receptacle (Fig. 8D-E: rs) and large, coarse-grained basophilic glands (Fig. 8E: g12), which are situated around the receptacle. The oviduct and vitelloducts are surrounded by weak, circular muscles. 
HOUBEN A.M. et al., Systematics of limnoterrestrial 'Typhloplanidae'

\section{Discussion}

See the general discussion on the genus Krumbachia.

\section{Remarks}

The bursa is filled mainly with some type of secretion. The seminal receptacle contains sperm and secretion.

\section{Previously known distribution}

A swamp, small stream, and pond near the University of Virginia, Virginia, USA (Kepner \& Carter 1931; Ruebush 1938).

\section{General discussion on Krumbachia}

The genus Krumbachia is the most species-rich genus within 'Protoplanellinae' (Van Steenkiste et al. 2010). Members of this genus can measure from $0.3 \mathrm{~mm}$ in the smallest species (i.e., K. minuta Ruebush, 1938) to over $3 \mathrm{~mm}$ in the largest one (i.e., K. paludicola Schwank, 1979 and K. virginiana (Kepner \& Carter, 1931) Ruebush, 1938). The diagnostic features are: lack of dermal rhabdites and presence of adenal rhabdites, presence of a sclerotised ejaculatory duct, and a pharynx with a median to posterior position. However, in practice, this genus is a conglomeration of animals roughly matching the diagnostic features (e.g., K. guttulata Schwank, 1980 possesses dermal rhabdites) and there are many similarities between the genera Krumbachia and Olisthanella Voigt, 1892 (see Ruebush 1938 for an elaborate discussion).

Krumbachia subterranea and K. virginiana possess the diagnostic features of the genus Krumbachia. Moreover, both are quite large species, lack eyes (but see further), have testes positioned rostral to the pharynx, and possess a strongly muscular bursa. There are only two other species that correspond to this description: K. paludicola and K. styriaca Reisinger, 1924.

Krumbachia virginiana strongly resembles $K$. paludicola because it has a bipartite bursa with strong muscles around its distal part. Krumbachia virginiana differs from K. paludicola in having a joint vas deferens, lacking a blindside branch on the ejaculatory duct, and lacking a large sphincter between the genital atrium and male copulatory system. In the original description, Kepner \& Carter (1931) mention the fact that the dark colouration in their specimens of $K$. virginiana disappears when the animals are starved for a weak, except for two tiny black spots that, according to them, may be eyes. As we did not starve the animals, this could not be confirmed. Krumbachia paludicola has a wide European distribution, whereas $K$. virginiana has a Nearctic distribution.

In his extensive redescription of $K$. virginiana, Ruebush (1935) mentions intraspecific variability in several features, leading to the description of a new variety: $K$. virginiana var. glandulosa. The identification of this variety is based on the position of the pharynx, subtle differences in the construction of the adenal rhabdite tracks, and the lack of a seminal receptacle in $K$. virginiana var. glandulosa. The latter character is considered a doubtful one by Ruebush (1935), as this may depend on the condition of the animal. The specimens studied by us show all characteristics of the nominal $K$. virginiana.

Krumbachia subterranea is morphologically similar to $K$. styriaca, and its description was based mainly on three differences (see Reisinger 1933). First, K. styriaca has a thin, sclerotised bursa with many bends and knicks, while it is a flattened, broad sack in K. subterranea. Second, the female duct in $K$. styriaca possesses a pronounced bend at the point where the female glands occur, while no such bend occurs in K. subterranea. Furthermore, the transition between the female duct and bursal stalk is very smooth in the latter species. Third, the vitellaria have small branches in K. subterranea, while they are 
very smooth in K. styriaca. These branches are not that pronounced in our specimens, and also do not seem strongly developed in the specimens studied by Schwank (1981: fig. 5).

Genus Olisthanellinella Reisinger, 1924

Olisthanellinella rotundula Reisinger, 1924

Fig. 9

\section{Material examined}

AUSTRIA - 3 specs, studied alive, one of which sagittally sectioned and one of which horizontally sectioned; Graz, Kanzelkügel; 47 $06^{\prime} 49^{\prime \prime}$ N, $15^{\circ} 23^{\prime} 11^{\prime \prime}$ E; 26 Aug. 2011; A.M. Houben and W. Proesmans leg.; forest soil; XIV.2.49-XIV.2.50; HU.

\section{Description and discussion}

The body length of the studied specimens is about $0.8 \mathrm{~mm}$. Habitus and internal organisation correspond to the original description (Reisinger 1924). The most typical characteristics of this monospecific genus are: adenal rhabdites (Fig. 9A: ar) occurring only in rostral tracks; dermal rhabdites absent; a bipartite bursa (Fig. 9A-D: bu) with a muscular, sclerotised stalk (Fig. 9B, D: bs) and a thin-walled proximal part; and the copulatory organ (Fig. 9A: co) with a muscular ejaculatory duct (Fig. 9B, D: de) and a large seminal receptacle (Fig. 9C: rs) that opens into the oviduct (Fig. 9C: od). The opening of the vitelloduct was never clearly observed. Neither of our sectioned specimens clearly show both male and female reproductive structures. Therefore, and because of (for now) intraspecific differences (see below), we refrain from designating a neotype.

Specimens described by Luther (1963) seem to be somewhat different from those described by Reisinger (1924) since they possess an egg-shaped bursa instead of a bipartite bursa and their oviduct functions as the seminal receptacle. Moreover, the specimens collected by Armonies (1987) were identified based on Luther's (1963) description. As probably is the case for all protoplanellins, a thorough molecular analysis would help to solve which features are apomorphic/diagnostic for the taxon and help identification and delimitation of species. Therefore, we provisionally keep all within Olisthanellinella rotundula.

\section{Previously known distribution}

In the vicinity of Graz, Austria in moist forest soils (Reisinger 1924); North-East Alps, Austria in moist forest soil (An der Lan \& Franz 1954); Oldenburg, Germany in humus of oak leaves (Reisinger in Luther 1963); Helsingfors, Finland in moss (Luther 1963); Sylt, Germany, in salt meadows (Armonies 1987).

Genus Prorhynchella Ruebush, 1939

Prorhynchella minuta Ruebush, 1939

Fig. 10

\section{Material examined}

USA - 9 specs, live observations, one of which sagittally sectioned and two horizontally sectioned;

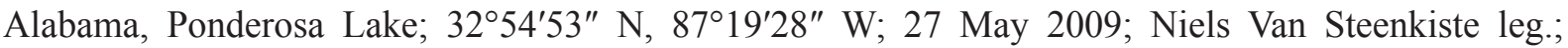
submerged vegetation in shallow, clear water in the southeast corner of the lake; XIV.3.01-XIV.3.03; HU. 


\section{Description and discussion}

Specimens are about $1 \mathrm{~mm}$ long (Fig. 10E) and can be placed within 'Protoplanellinae' due to the ventral position of the testes relative to the vitellaria and the separate protonephridiopores (see Reisinger 1924). Additionally, sectioned specimens clearly show ciliated pits (Fig. 10B: cp) at the anterior body
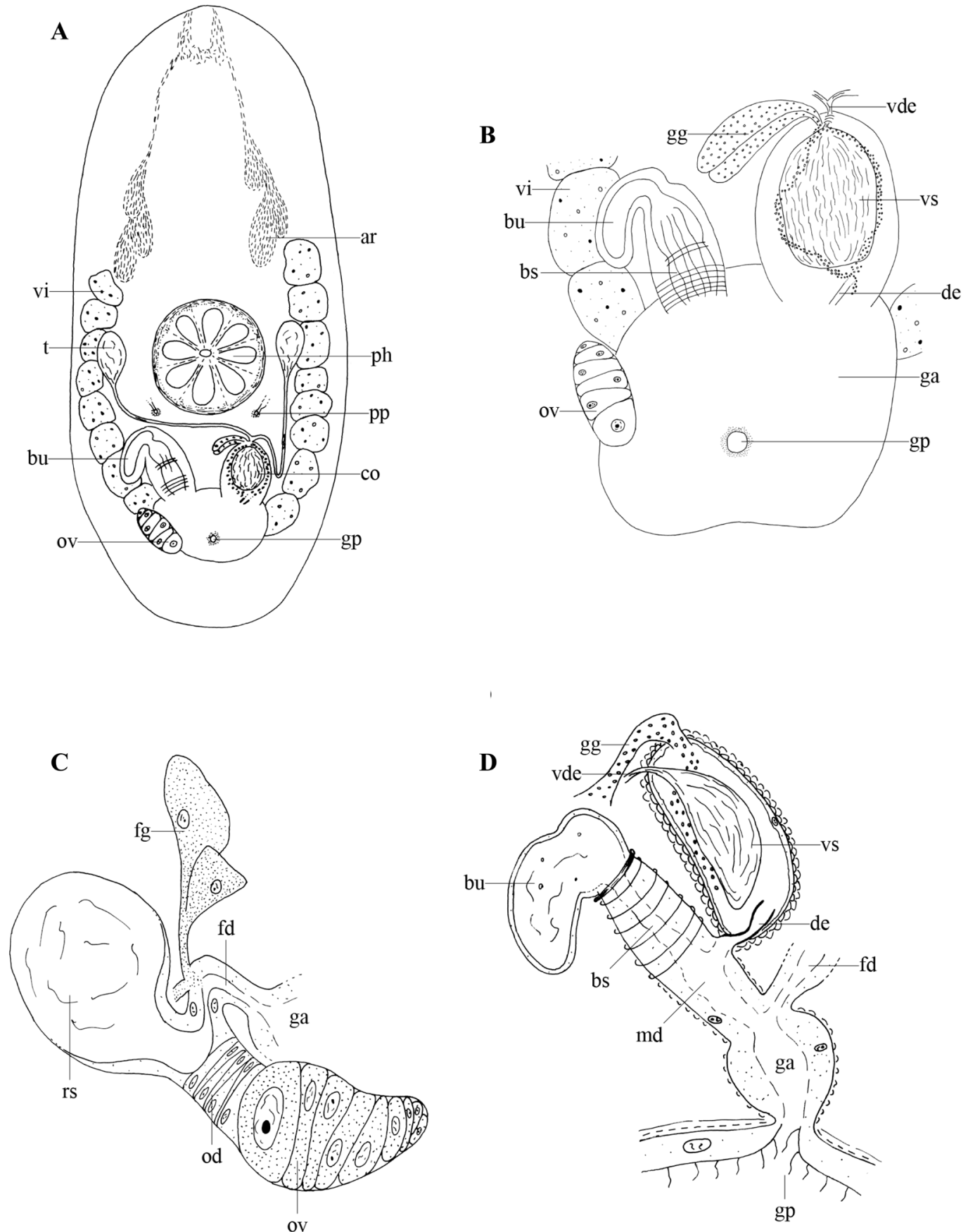

Fig. 9. Olisthanellinella rotundula Reisinger, 1924. A. Internal organisation of a live specimen. B. Organisation of the genital system of a live specimen. C. Reconstruction of female reproductive organs based on horizontal sections. D. Reconstruction of male reproductive organs based on sagittal sections. 
end. Within 'Protoplanellinae', the only genus containing species with such pits is Prorhynchella (Van Steenkiste et al. 2010). Moreover, the studied specimens also possess the typical proboscis-like organ (Fig. 10B: plo) associated with a glandular complex (Fig. 10B: gl) that is unique for this monospecific genus (described as 'rüssel-like organ' by Ruebush 1939).

The only difference between our specimens and the original description of $P$. minuta is the position of the protonephridiopores (Fig. 10A: pp), which are situated somewhat more posteriorly compared to the original description (Ruebush 1939).

The studied specimens show some intraspecific variation in the structure of the bursa (Fig. 10A, C-F: bu). In one specimen, this is merely an evagination of the genital atrium while in another it is an oval, thin-walled structure, filled with sperm (compare Fig. 10C-D, F). It is connected to the genital atrium (Fig. 10A, D: ga) by a long bursal stalk (Fig. 10C, F: bs), which is surrounded by very strong sphincters (Fig. 10C, F: sph). Only two sphincters were visible on live specimens (Fig. 10F), but at least six were counted in one sectioned specimen (Fig. 10C). In the original description of P. minuta, Ruebush (1939) describes a bursa with a stalk, similar to the situation in most of our specimens (Fig. 10C, F). Whether or not the specimen drawn in Fig. 10D is an aberration is not clear: The specimen appears fully adult, hence the poorly developed bursal structure is unlikely a result of a different degree of development. With the data available to us, it is difficult to speculate on the biological significance of this reduced organ and we hence refrain from drawing conclusions on the matter.

\section{Previously known distribution}

Freshwater ponds near Pine Orchard, Connecticut, USA (Ruebush 1939).

Genus Protoplanella Reisinger, 1924

Protoplanella leiae Houben, Proesmans \& Artois sp. nov. urn:lsid:zoobank.org:act:449E44F6-12BB-4103-B70A-56E59B734A11

Protoplanella simplex - Luther 1963: 5, 13-14, fig. 1, taf. 1. - Van Steenkiste et al. 2011: 2, 6-7, fig. 3.

\section{Diagnosis}

'Protoplanellinae' with adenal rhabdites anterior, dermal rhabdites absent. Eyes absent. Pharynx centrally positioned. Paired, globular testes occur laterally behind the pharynx. Vasa deferentia unite while entering the copulatory organ proximally. Copulatory organ with straight, muscular ejaculatory duct. Female bursa present. Blind sack attached to the genital atrium.

\section{Etymology}

The species epithet is dedicated to Leia Houben, youngest daughter of the first author (A.M. Houben).

\section{Material examined}

\section{Holotype}

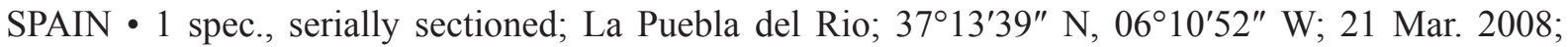
Van Steenkiste et al. 2011 leg.; mosses on bank of dried up temporal brook in open coniferous forest; KV.689; FMNH.

\section{Paratype}

SPAIN • 1 spec., serially sectioned; same collection data as for holotype; paratype no. 824; HU. 

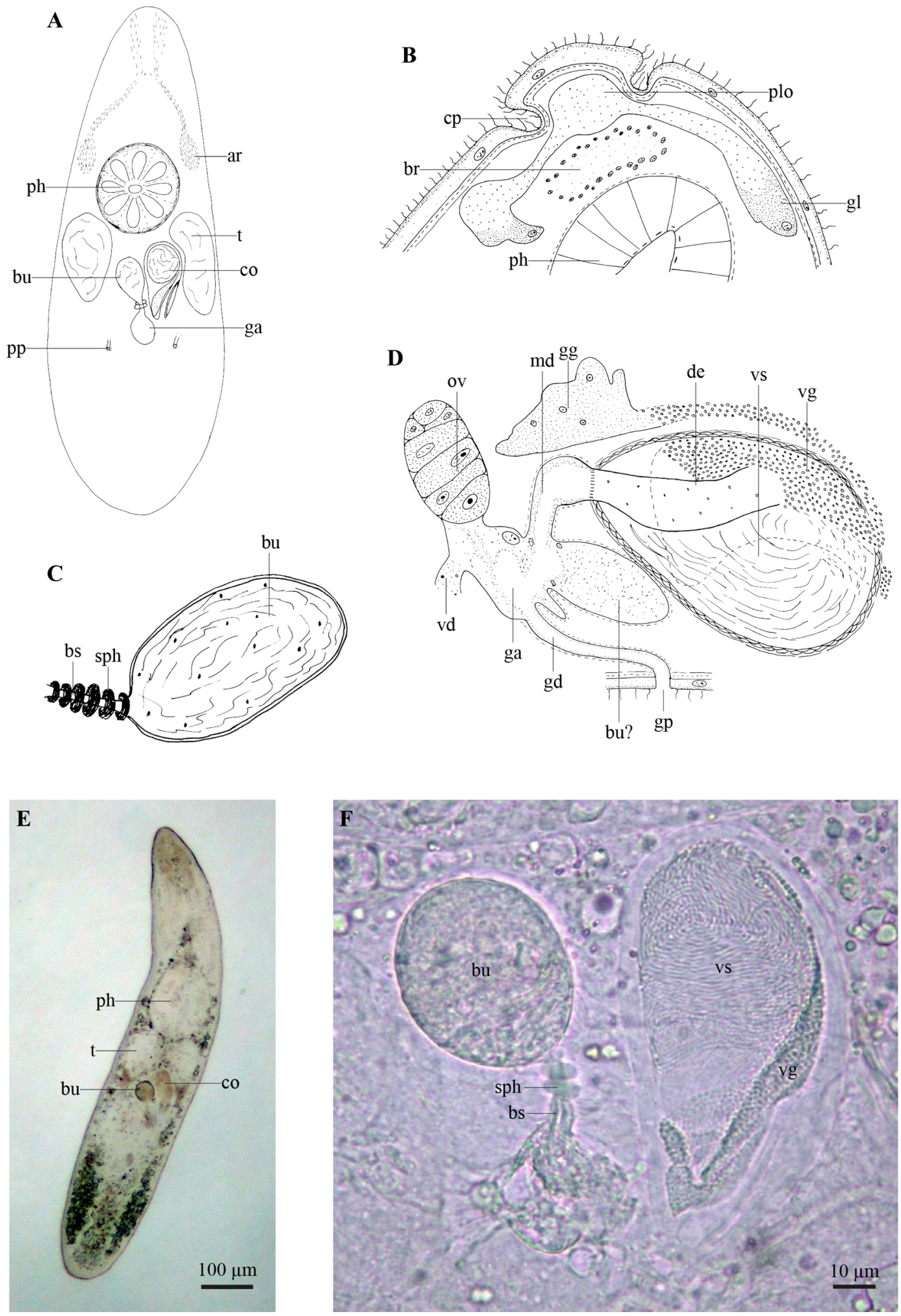

Fig. 10. Prorhynchella minuta Ruebush, 1939. A. Internal organisation of a live specimen. B. Reconstruction of the anterior body part based on horizontal sections. C. Reconstruction of a fully developed bursa based on horizontal sections. D. Reconstruction of reproductive organs based on sagittal sections. E. Squash preparation of a live specimen. F. Detail of the genital system of a live specimen. 


\section{Description}

Van Steenkiste et al. (2011) gave an excellent description of this animal, albeit described as Protoplanella simplex. Therefore, we refer to this publication for the illustration and description of Protoplanella leiae Houben, Proesmans \& Artois sp. nov.

\section{Discussion}

See the general discussion on the genus Protoplanella Reisinger, 1924.

\section{Previously known distribution}

Tvärminne, Finland in mosses (Luther 1963; as Protoplanella simplex). La Puebla del Rio, Spain (Van Steenkiste et al. 2011; as P. simplex).

Protoplanella simplex Reisinger, 1924

Fig. 11

\section{Material examined}

\section{Neotype}

GERMANY • 1 spec., live observations and sagittal sections; Kordel; 49 49'24" N, 06³8'06" E; 24 Jul. 2011; A.M. Houben and W. Proesmans leg.; mosses growing on a wall; neotype no. 825; HU.

\section{Other material}

GERMANY • 1 spec., serially sectioned; same collection data as for neotype; XIV.3.11; HU 2 specs,

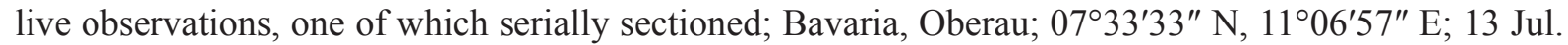
2011; A.M. Houben and W. Proesmans leg.; forest litter; XIV.3.12; HU • 5 specs, live observations, three of which serially sectioned; Lanaken; 50 56'03" N; 05³9'36" E; 27 Jul. 2011; A.M. Houben and W. Proesmans leg.; mosses at the forest edge; XIV.3.13-XIV.3.15; HU • 4 specs, live observations, two of which serially sectioned; Lanaken, National Park 'Hoge Kempen'; 50 56 $02^{\prime \prime}$ N; 05 39'38" E; 27 Jul. 2011; A.M. Houben and W. Proesmans leg.; moist forest soil; XIV.3.16-XIV.3.17; HU.

\section{Description}

The studied specimens are about $0.8 \mathrm{~mm}$ long. The anterior and posterior body ends are rounded (Fig. 11A). Rhabdite glands are present and arranged into two groups behind the brain (Fig. 11A: ar); the rhabdites themselves extend forward in two anastomosing tracts. Dermal rhabdites were not observed. The paired protonephridiopores (Fig. 11A: pp) open laterally and somewhat caudal to the rosulate pharynx (Fig. 11A, C: ph), which is situated just behind the middle of the body.

The gonopore (Fig. 11A-C: gp) is located at $\pm 80 \%$ of the body and connected to a genital atrium (Fig. 11A-C: ga). The genital atrium is surrounded by an inner circular and outer longitudinal muscle layer.

The small, round testes (Fig. 11A-B: t) lie posterior to the pharynx and ventral to the vitellaria (Fig. 11A-C: vi). Both vasa deferentia (Fig. 11B-C: vde) enter the copulatory organ (Fig. 11A: co) separately from the lateral side. This $22 \mu \mathrm{m}$ long, oval-shaped copulatory organ is surrounded by two layers of spiral muscles and contains an intracapsular seminal vesicle (Fig. 11B-C: vs) with a low, nucleated epithelium and an ejaculatory duct (Fig. 11B-C: de), which is surrounded by two layers of spiral muscles. Extracapsular, eosinophilic prostate glands (Fig. 11A-C: gg) open laterally into the copulatory organ. A male duct (Fig. 11C: $\mathrm{md}$ ) with the same musculature as the genital atrium connects the copulatory organ to the latter. 
The paired vitellaria extend from $25 \%$ of the body to the posterior end where they fuse via a broad anastomosis. A single ovary (Fig. 11A-C: ov) is closely associated with one of the vitellaria forming an ovovitellarium. The female duct (Fig. 11C: fd) is surrounded by the same musculature as the genital atrium and receives a club-shaped seminal receptacle (Fig. 11A-C: rs) and ovovitelloduct at its proximal end. Fine-grained, eosinophilic glands (Fig. 11C: fg) surround and enter the female duct.

\section{Discussion}

See the general discussion on the genus Protoplanella.

\section{Remarks}

Intensive surveys at the type locality yielded no specimens. The specimens from Oberau, Bavaria, Germany, which is relatively close to the original type locality in Graz, Austria, are of poor quality. Therefore, a specimen from Kordel, Germany was designated neotype, since all diagnostic features are exactly as described by Reisinger (1924).

\section{Previously known distribution}

In the vicinity of Graz, Austria in forest humus (Reisinger 1924, 1954; An der Lan \& Franz 1954; An der Lan 1963), on the Faroe Islands (Steinböck 1931); near Poznań, Poland, in moss and litter (Kolasa 1974).

\section{General discussion on Protoplanella}

As mentioned by Van Steenkiste et al. (2011), the identification of Protoplanella simplex is challenging. New material found during several sampling trips showed a need for type material to unravel the morphological differences between all known descriptions of P. simplex. Reisinger (1924) originally described animals with round testes; vasa deferentia that open separately from the lateral side of the copulatory organ; a vitellarium and ovovitellarium connected to each other over a broad anastomosis; and a seminal receptacle that opens into the proximal part of the female duct. Luther (1963) described a specimen with elongated testes; a bursa that could be a seminal receptacle near the male copulatory organ; and, judging from his illustration, most probably paired ovovitellaria. Also, Van Steenkiste et al. (2011) describe a sack-like protrusion at the genital atrium (which was not mentioned by Reisinger 1924); a female bursa (which was called a seminal receptacle by Reisinger 1924) containing remnants of sperm; and their illustration shows the vasa deferentia uniting while entering the copulatory organ at the proximal side.

The descriptions of Luther (1963) and Van Steenkiste et al. (2011) differ substantially from that of Reisinger (1924) and, therefore, we consider them not to refer to representatives of $P$. simplex. Here, we consider these descriptions as referring to a new species: Protoplanella leiae Houben, Proesmans \& Artois sp. nov. Moreover, the description of Luther (1963) indicates some, albeit smaller, differences with that of Van Steenkiste et al. (2011). The illustration made by Luther (1963) is not detailed and only made from live specimens. Since Luther's drawings are in general more detailed, we assume this illustration was based on sub-ideal circumstances, which yielded a quickly made sketch. For now, we consider the specimens described by Luther (1963) and Van Steenkiste et al. (2011) to be members of the same species since differences are small and, in the case of Luther, not based on thoroughly studied material.

\section{Acknowledgments}

We thank Mrs Natascha Steffanie for preparing histological sections and Mrs Ria Vanderspikken for administrative support. Dr Niels Van Steenkiste is gratefully acknowledged for his sampling efforts in Canada and Alabama. Dr Jurek Kolasa and Dr Paul Davison are thanked for their assistance during 
fieldwork and for offering lab space in Canada and the USA. AH was supported by a BOF grant of Hasselt University. MM was funded by a $\mathrm{PhD}$ fellowship from the Research Foundation - Flanders (FWO-Vlaanderen). This paper is a contribution to project G.08.208 financed by FWO-Vlaanderen. Part of the research leading to results presented in this publication was carried out with infrastructure funded by EMBRC Belgium - FWO project GOH3817N. We thank two referees for their careful review of this manuscript.

\section{References}

An der Lan H. 1963. Zur Verbreitung edaphischer Kleinturbellarien in Österreich. Berichte des Naturwissenschaftlich-Medizinischen Vereins in Innsbruck 53: 227-234.

An der Lan H. \& Franz H. 1954. Turbellaria. In: Franz H. (ed.) Die Nordost-Alpen im Spiegel ihrer Landtierwelt: 129-134. Universitätsverlag Wagner, Innsbruck.

Armonies W. 1987. Freilebende Plathelminthen in supralitoralen Salzwiesen der Nordsee: Ökologie einer borealen Brackwasser-Lebensgemeinschaft. Microfauna Marina 3: 81-156.
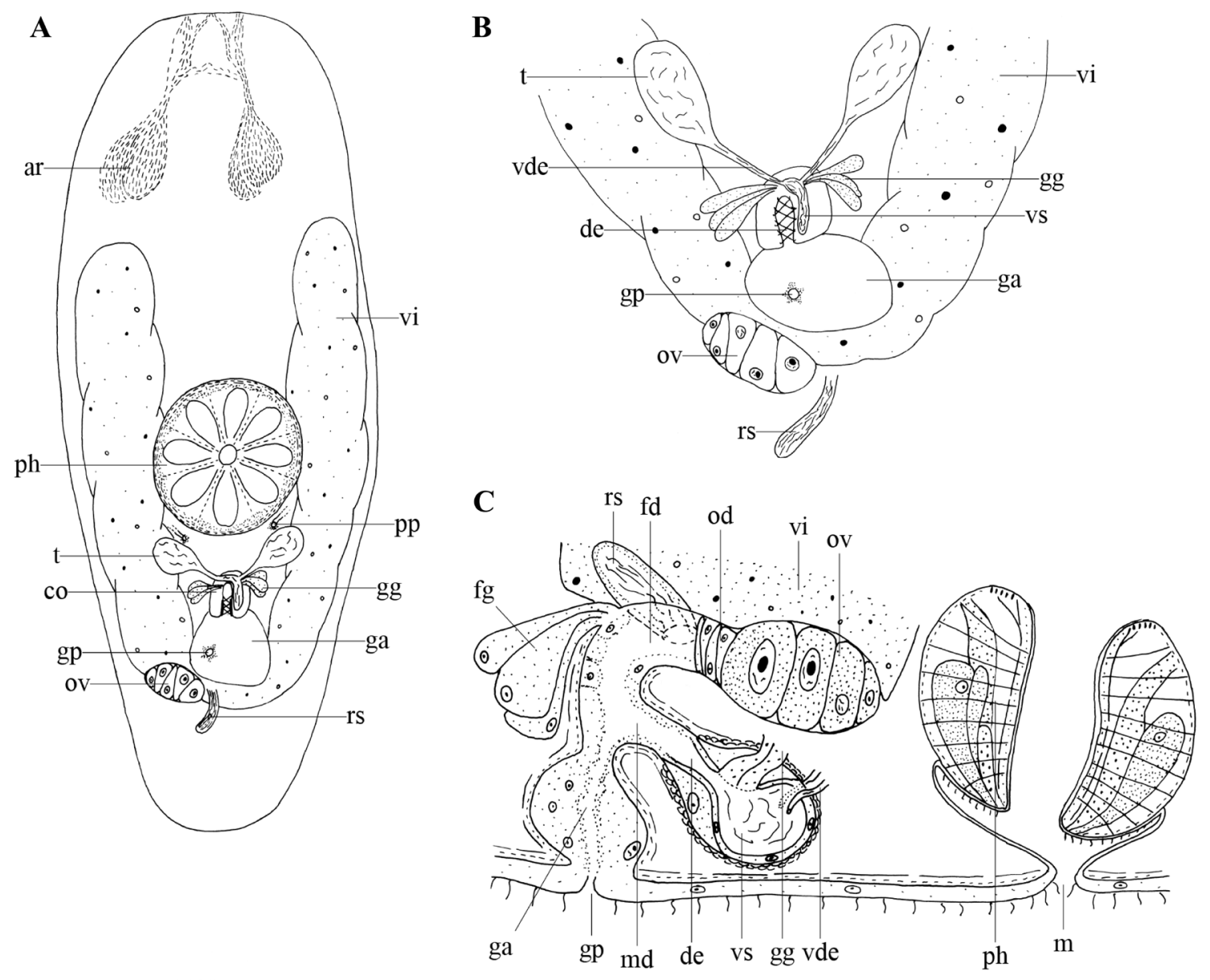

Fig. 11. Protoplanella simplex Reisinger, 1924. A. Internal organisation of a live specimen. B. Organisation of the genital system of a live specimen. C. Reconstruction of reproductive organs based on sagittal sections of the neotype (neotype no. 825). 
HOUBEN A.M. et al., Systematics of limnoterrestrial 'Typhloplanidae'

Ax P. 2008. Plathelminthes aus Brackgewässern der Nordhalbkugel. Akademie der Wissenschaften und der Literatur. Franz Steiner Verlag, Stuttgart.

Ehlers U. 1974. Interstitielle Typhloplanoida (Turbellaria) aus dem Litoral der Nordseeinsel Sylt. Mikrofauna des Meeresbodens 49: 427-526.

ICZN 1999. International Code of Zoological Nomenclature. Fourth edition. The International Trust for Zoological Nomenclature, London, UK.

Houben A. 2013. Diversity and phylogeny of the limnoterrestrial Rhabdocoela (Platyhelminthes), an enigmatic group of minute metazoans. PhD thesis, Hasselt University, Diepenbeek, Hasselt, Belgium.

Houben A.M., Schwank P., Proesmans W., Bert W. \& Artois T.J. 2015. Notes on some enigmatic taxa of limnoterrestrial rhabdocoels, with the description of two new species. Zootaxa 4040 (1): 083-092. https://doi.org/10.11646/zootaxa.4040.1.7

Karling T.G. 1957. Drei neue Turbellaria Neorhabdocoela aus dem Grundwasser der schwedischen Ostseeküste. Kungliga fysiografiska sällskapets i Lund förhandlingar 27: 25-33.

Kepner W.A. \& Carter J.S. 1931. Olisthanella virginiana nov. sp. Zoologischer Anzeiger 95: 87-94.

Kolasa J. 1974. Badania nad wirkami (Turbellaria) źródeł ze szczególnym uwzględnieniem okolic Poznania (The investigations on spring Turbellaria with a special regard to surroundings of Poznań). Badania Fizjograficzne nad polska zachodnia 26: 7-31.

Kolasa J. 1977. A new representative of terrestrial Typhloplanoida (Turbellaria) - Ventrociliella romanae gen. nov., sp. nov. Bulletin de l'Académie polonaise des sciences. Série des sciences biologiques 25: $39-43$.

Kolasa J. 1981a. New Protoplanellinae (Turbellaria, Typhloplanidae) from semiterrestrial habitats in Poland: Adenocerca teshirogii sp. nov., Krumbachia microbursalis sp. nov. Bulletin de l'Académie polonaise des sciences. Série des sciences biologiques 28 (10-11): 593-610.

Kolasa J. 1981b. New semiterrestrial species of Protoplanellinae (Turbellaria, Typhloplanidae) associated with a submontane stream. Bulletin de l'Académie polonaise des sciences. Série des sciences biologiques 28 (10-11): 611-616.

Lanfranchi A. \& Papi F. 1978. Turbellaria (excl. Tricladida). In: Illies J. (ed.) Limnofauna Europaea: 5-18. G. Fischer, Stuttgart.

Luther A. 1963. Die Turbellarien Ostfennoskandiens IV. Neorhabdocoela 2. Typhloplanoida: Typhloplanidae, Solenopharyngidae und Carcharodopharyngidae. Fauna Fennica 16: 1-163.

Nixon K.C.\& Wheeler Q.D. 1990. An amplification of the phylogenetic species concept. Cladistics 6: 211-223. https://doi.org/10.1111/j.1096-0031.1990.tb00541.x

Reisinger E. 1924. Die terricolen Rhabdocoelen Steiermarks. Zoologischer Anzeiger 59: 33-48, 72-86, $128-143$.

Reisinger E. 1933. Neues zur vitalen Nervenfärbung. (Gleichzeitig ein Beitrag zur Kenntnis des Protoplanelliden-Nervensystems). Verhandlungen der deutschen Zoologischen Gesellschaft: 155-160.

Reisinger E. 1954. Edaphische Kleinturbellarien als bodenkundliche Leitformen. Mitteilungen des Naturwissenschaftlichen Vereines für Kärnten 64: 106-123.

Rieger R.M. 1974. A new group of Turbellaria-Typhloplanoida with a proboscis and its relationship to Kalyptorhynchia. In: Riser-Marx (ed.) The Biology of the Turbellaria: 23-62. McGraw-Hill, New York.

Ruebush T.K. 1935. The genus Olisthanella in the United States. Zoologischer Anzeiger 112: 129-136. 
Ruebush T.K. 1938. Krumbachia minuta n. sp. (Turbellaria Rhabdocoela). Zoologischer Anzeiger 122: 260-265.

Ruebush T.K. 1939. A new North American rhabdocoel turbellarian Prorhynchella minuta n. gen., n. sp. Zoologischer Anzeiger 127: 204-209.

Schockaert E.R. 1996. Turbellarians. In: Hall G.S. (ed.) Methods for the Examination of Organismal Diversity in Soils and Sediments: 211-226. CAB International, United Kingdom.

Schwank P. 1981. Seltene und wenig bekannte Strudelwürmer (Turbellaria) aus Quellen und Bergbächen Mitteleuropas. Beiträge zur Naturkunde in Osthessen 17: 101-131.

Steinböck O. 1931. Freshwater Turbellaria. In: Jensen S., Lundbeck W. \& Mortensen Th. (eds) Zoology of the Faroes: 1-32. Copenhagen.

Townshend J.L. 1963. A modification and evaluation of the apparatus for the Oostenbrink direct cotton wool filter extraction method. Nematologica 9: 106-110. https://doi.org/10.1163/187529263X00205

Tyler S., Schilling S., Hooge M. \& Bush L.F. 2006-2021. Turbellarian taxonomic database. Version 1.7. Available from http://turbellaria.umaine.edu [accessed 11 Feb. 2022].

Van Steenkiste N., Davison P. \& Artois T. 2010. Bryoplana xerophila n. g. n. sp., a new limnoterrestrial microturbellarian (Platyhelminthes, Typhloplanidae, Protoplanellinae) from epilithic mosses, with notes on its ecology. Zoological Science 27 (3): 285-291. https://doi.org/10.2108/zsj.27.285

Van Steenkiste N., Tessens B., Krznaric K. \& Artois T. 2011. Dalytyphloplanida (Platyhelminthes: Rhabdocoela) from Andalusia, Spain, with the description of four new species. Zootaxa 2791: 1-29. https://doi.org/10.11646/zootaxa.2791.1.1

WoRMS. 2021. "Rhabdocoela." Available from

www.marinespecies.org/aphia.php? $\mathrm{p}=$ taxdetails\&id=16236 [accessed 14 Sep. 2021].

Manuscript received: 25 October 2021

Manuscript accepted: 16 December 2021

Published on: 1 March 2022

Topic editor: Tony Robillard

Section editor:Martin Vinther Sorensen

Desk editor: Eva-Maria Levermann

Printed versions of all papers are also deposited in the libraries of the institutes that are members of the EJT consortium: Muséum national d'histoire naturelle, Paris, France; Meise Botanic Garden, Belgium; Royal Museum for Central Africa, Tervuren, Belgium; Royal Belgian Institute of Natural Sciences, Brussels, Belgium; Natural History Museum of Denmark, Copenhagen, Denmark; Naturalis Biodiversity Center, Leiden, the Netherlands; Museo Nacional de Ciencias Naturales-CSIC, Madrid, Spain; Real Jardín Botánico de Madrid CSIC, Spain; Zoological Research Museum Alexander Koenig, Bonn, Germany; National Museum, Prague, Czech Republic. 